\title{
El dimorfismo sexual en guanacos (Lama guanicoe). Una evaluación osteométrica de elementos poscraneales
}

\section{RMA}

Dossier - Arqueología

Cristian Kaufmann ${ }^{1}$

G. Lorena L'Heureux ${ }^{2}$

${ }^{1}$ CONICET-INCUAPA, Departamento de Arqueología. Facultad de Ciencias Sociales, Universidad del Centro de la Provincia de Buenos Aires.

E-mail:ckaufman@soc.unicen.edu.ar

${ }^{2}$ CONICET-IMHICIHU, Departamento de Investigaciones Prehistóricas y Arqueológicas (DIPA). E-mail: lorenalheureux@yahoo.com.ar

\section{Resumen}

En poblaciones vivas, los camélidos silvestres sudamericanos son sexados a partir de la observación de su conducta social y reproductiva. Por lo general, tanto biólogos como arqueólogos asumen la ausencia de caracteres morfológicos que evidencien un dimorfismo sexual marcado entre individuos adultos de guanaco (Lama guanicoe). Los principales estudios que evalúan las diferencias osteológicas entre machos y hembras en esta especie están basados en análisis de variables morfométricas craneanas y en caracteres morfológicos de la pelvis. En este trabajo se evalúa la existencia y magnitud de variables osteométricas poscraneales de diferenciación sexual en una población moderna de guanacos procedente de la localidad Cinco Chañares, Provincia de Río Negro, Argentina. Se estudiaron 32 individuos (8 machos y 24 hembras) de más de 30 meses en los que se midieron 51 hemipelvis, 40 húmeros, 39 radioulnas, 40 fémures y 41 tibias. Los resultados mostraron que las principales diferencias osteológicas, vinculadas con el dimorfismo sexual, se relacionan con variaciones en el tamaño y la forma de la pelvis. En los huesos largos, las diferencias osteométricas significativas se registraron sólo en variables aisladas y no se pudieron definir diferencias osteométricas asociadas con el dimorfismo sexual. Igualmente se considera que esto deberá ser reevaluado con mayor profundidad considerando una muestra mayor de individuos machos.

Palabras clave: guanaco, dimorfismo sexual, morfometría, pelvis, huesos largos.

Sexual dimorphism in guanacos (Lama guanicoe). An osteometric evaluation of postcranial elements

\begin{abstract}
In wild-living populations adult camelids are mainly sexed by observing their social and reproductive behavior, and on occasion, their genitalia. Both biologists and archaeologists usually assume the absence of clearly identifiable sexually dimorphic somatic and postcranial traits among adult guanaco (Lama guanicoe) specimens. The principal studies that evaluate the osteological differences between sexes in this species, had been carried out using qualitative morphological traits of the pelvis and morphometric traits of the skull. Therefore, the main objective of this paper is to contribute to the development of methodological tools aimed to accurately discriminate between sexes using morphometric techniques. In addition, we assess in this paper the existence and magnitude of the postcranial sex-related morphometric differences in a sample of modern guanaco specimens from Cinco Chañares, Río Negro, Argentina. The sample was composed by 32 individuals (8 males and 24 females) older than 30 month at the age of death. Fifty one hemipelvis, 40 humeri, 39 radioulnae, 40 femora, and 41 tibiae were measured. The obtained results show that the main morphometric differences between sexes are related to size and shape variation in the whole pelvis and acetabulum. In the appendicular skeleton no statistically significant differences between sexes were found, but this ought to be reevaluated increasing sample sizes of male specimens.
\end{abstract}

Keywords: guanaco, sexual dimorphism, morphometry, pelvis, long bones.

El sexo y la edad constituyen parámetros demográficos de importancia, tanto en los estudios de poblaciones modernas de Lama guanicoe (Müller 1776), como en el análisis de los restos óseos arqueológicos y paleontológicos de guanaco. Desde el punto de vista del estudio demográfico actual de esta especie, estos parámetros son indispensables en las investigaciones de dinámica poblacional que tienen como objetivo el diseño de programas de manejo para su recuperación o aprovechamiento sostenido (Saba et al. 1995). Por otro lado, el análisis de la estructura sexual y etaria de los conjuntos zooarqueológicos aporta valiosa información para identificar la estrategia de caza empleada por los cazadores y conocer si los mismos se concentraron sobre algún grupo social en particular (O'Connor 2006; Reitz y Wing 1999; Steele 2002, 2003; Stiner 1990). Estudios realizados sobre dis- 
tintos mamíferos demuestran que la calidad de la carne, médula, órganos internos y piel, así como la vulnerabilidad y disponibilidad de los animales, varían de acuerdo con el sexo y la edad (Speth 1983; Steele 2002).

La determinación sexual de los restos óseos de animales se basa en la identificación de caracteres sexuales de primer, segundo y tercer orden (Ruscillo 2003, 2006). Los caracteres sexuales de primer orden corresponden a rasgos relacionados directamente con los órganos de reproducción sexual (e.g. la presencia de baculum en los machos de algunas especies de mamíferos). Los caracteres sexuales de segundo orden se relacionan con las conductas sexuales que tienen como objetivo la adquisición de pareja y la reproducción (e.g. presencia y/o mayor desarrollo de cuernos, astas o grandes caninos en cérvidos). Los caracteres sexuales de tercer orden se definen como rasgos desarrollados bajo la influencia directa del uso y desarrollo de caracteres primarios y secundarios. Estos últimos surgen durante la vida, como respuesta a una conducta sexual o a una diferenciación fisiológica entre sexos (e.g. morfología y estructura pélvica en los mamíferos).

Los estudios biométricos y osteométricos, realizados tanto en Lama guanicoe como en el resto de los camélidos sudamericanos, afirman que el dimorfismo sexual en estas especies es nulo o poco evidente (Cartagena 2002, 2007; Mengoni Goñalons y Yacobaccio 2006; Merino y Cajal 1993; Moore 1989; Vilá 2000; Yacobaccio 2006). Los individuos vivos son sexados a partir de la observación de la conducta social y reproductiva, del pelaje y de la observación directa de los genitales (de Lamo 1983; Raedeke 1979; Fritz 1985; Saba et al. 1995). Cuando sólo se cuenta con el esqueleto, el cual carece de caracteres sexuales primarios, la determinación sexual se realiza con los elementos óseos más dimórficos, como el cráneo y la pelvis.

En el cráneo, se han aplicado diferentes procedimientos morfométricos, tales como la medición de la raíz y/o la corona de los caninos. Estos análisis mostraron diferencias significativas entre los sexos asociadas con el tamaño de los caninos (de Lamo 1983; Kaufmann 2009; Lefèvre et al. 2003; Raedeke 1978).

En la pelvis, a través de diferentes estudios osteológicos, se han reconocido rasgos morfológicos de diferenciación sexual en guanacos, como así también en vicuñas, llamas y alpacas (Cartajena 2007; Raedeke 1978, 1979). Los principales atributos diagnósticos identificados en la pelvis son: la tuberosidad suspensora del pene, en la arcada isquiática y la forma y espesor de la sínfisis púbica y del hueso ilíaco (Cartajena 2007; Raedeke 1978, 1979). Debe mencionarse que las estructuras óseas vinculadas con la identificación de caracteres sexuales se ubican en regiones relativamente frágiles de la pelvis. En este sentido, estas piezas suelen hallarse dañadas, fracturadas o ausentes en el registro zooarqueológico y/o paleontológico. El acetábulo corresponde a la región pélvica que aloja al fémur y presenta una gran densidad ósea, aumentando de esta manera la probabilidad de preservación de la pieza en el registro arqueológico y paleontológico. Asimismo, contrariamente con lo desarrollado para otras especies de mamíferos (e.g. Greenfield 2006; Grigson 1982; Prummel y Frisch 1986; Ruscillo 2003), esta estructura no ha sido contemplada para la diferenciación sexual en camélidos sudamericanos.

Diversos estudios osteométricos han demostrado que numerosas especies de bóvidos, cérvidos, proboscídeos, cánidos y otáridos, entre otros mamíferos, presentan un destacado dimorfismo sexual interpretado a partir del tamaño corporal (e.g. Reher y Frison 1980; Grigson 1982; Speth 1983; Davis 1987; Sedlácková 2006; Higham et al. 1980; Rusillo 2006; Morrison y Whitridge 1997; Crespo 1988; Weinstock 2000), siendo los machos de mayor tamaño respecto de las hembras. No obstante, el esqueleto apendicular de los guanacos ha suscitado poca atención en los estudios de diferenciación sexual, probablemente debido a que las observaciones directas sobre animales vivos de esta especie señalan que el tamaño de los individuos se encuentra entre los rasgos sexualmente menos dimórficos. Raedeke (1979) evaluó el dimorfismo sexual en guanacos modernos considerando las variables: peso corporal, longitud del cuerpo, longitud de las patas traseras y longitud de la mandíbula. Los resultados obtenidos mostraron que las diferencias entre machos y hembras no son marcadas, que los machos pesan menos que las hembras y que resultan más pequeños que éstas al considerar algunas variables, y más grandes tomando en cuenta otras. Yacobaccio (2006) realizó un estudio biométrico en vicuñas obteniendo resultados similares, confirmando de este modo la ausencia de dimorfismo sexual en el tamaño corporal de los camélidos sudamericanos.

Sumado a estos antecedentes, la posibilidad de identificación sexual en colecciones arqueofaunísticas, en las que los agentes antrópicos y naturales han condicionado la representación anatómica favoreciendo la fragmentación ósea, constituye un problema que continúa vigente. De acuerdo con lo planteado, el objetivo de este trabajo es evaluar la existencia y magnitud de variaciones morfométricas asociadas con el sexo en elementos óseos poscraneales de guanaco (pelvis y huesos largos), a fin de incrementar el número de indicadores que posibiliten la estimación del sexo a través de los restos óseos de muestras de origen arqueológico y/o paleontológico.

\section{Materiales y métodos}

El presente estudio se llevó a cabo con ejemplares modernos de la especie Lama guanicoe procedentes de la localidad de Cinco Chañares, departamento de San Antonio, provincia de Río Negro, Patagonia Argentina $\left(40^{\circ}\right.$ $33^{\prime}-40^{\circ} 40^{\prime} \mathrm{S}$ y $65^{\circ} 11^{\prime}-65^{\circ} 32^{\prime} \mathrm{O}$ ). Esta región posee un clima árido, de tipo semi-desértico y templado, fuertemente condicionado por los vientos secos que penetran al continente desde el oeste y noroeste (Guarido y Mazzitelli 
2003). El área se encuentra en la provincia Biogeográfica del Monte, la cual ocupa una gran extensión del territorio argentino (paralelo 27 al 44: desde la provincia de Salta hasta el nordeste de Chubut; Cabrera y Willink 1980). La localidad de Cinco Chañares se encuentra incluida en la subregión Monte Austral (Morello 1958), limitando al norte con la provincia del Espinal y al suroeste con la provincia Patagónica.

La muestra estudiada en este trabajo está representada por las carcasas de 32 individuos silvestres (ocho machos y veinticuatro hembras) de más de 30 meses de edad con la totalidad de sus huesos largos y acetábulos pélvicos fusionados. Estos esqueletos tienen distintos grados de integridad y algunos de sus huesos están ausentes o dañados por agentes tafonómicos por lo cual no fueron medidos. La edad de los individuos fue estimada en base al análisis de los dientes considerando la clave de edad elaborada por Oporto et al. (1979) y de Lamo (1990). El sexo fue determinado por observación genital, examen visual de los rasgos morfológicos de la sínfisis púbica y arcada isquiática de la pelvis y el análisis métrico de los caninos (ver Kaufmann 2009). Se estudiaron 211 elementos poscraneales': 51 hemipelvis, 40 húmeros, 39 radioulnas, 40 fémures y 41 tibias. En estos especímenes se relevaron 106 variables continuas ${ }^{2}$ que fueron adoptadas de dife-

1 Aquí se describe la mayor cantidad de huesos medidos por elemento, pero el $\mathrm{N}$ varía de acuerdo a si se trata del hueso completo o de algún segmento del mismo. Las muestras de los elementos completos resultan menores que las muestras de las epífisis de los huesos largos y/o acetábulos debido a que los huesos enteros se encuentran en ocasiones fragmentados $y / o$ exfoliados en sectores que impiden obtener alguna/s de las medidas.

2 La guía de medidas de los huesos largos utilizada en este trabajo se desarrolla en L'Heureux (2008). Las variables medidas en la pelvis forman parte de una guía osteométrica definida especialmente para este elemento (L'Heureux 2009a). rentes estándares diseñados para mamíferos medianos y grandes (e.g. Davis 1996; Kent 1982; Speth 1983; Von den Driesch 1976). Las medidas se obtuvieron con calibre digital $(0,01 \mathrm{~mm}$ de precisión) y tabla osteométrica. La información fue procesada mediante la aplicación de técnicas estadísticas univariadas y multivariadas (Análisis de Componentes Principales -ACP-; Análisis de varianza: ANOVA one-way), empleando los softwares SPSS V.15 y SYSTAT 10.2. El valor de probabilidad considerado como significativo fue de $0,05(P<0,05)$.

Debido a que las técnicas morfológicas tradicionales tienen dificultades para distinguir en el análisis estadístico las variaciones métricas de tamaño de las de forma, se decidió utilizar tanto los datos sin estandarizar como aquellos estandarizados para inspeccionar ambos aspectos morfológicos (tamaño y forma) en los huesos estudiados. Entonces, para inspeccionar las variaciones asociadas con el tamaño se consideraron los análisis de ANOVA y el primer componente principal de los ACP realizados con las variables sin estandarizar. Por otro lado, para evaluar las variaciones morfológicas asociadas con la forma se utilizaron sólo las variables estandarizadas en el ACP. El procedimiento de la estandarización de los datos propone llevar todos los valores a una misma escala con el objeto de eliminar el "efecto tamaño" y aislar las variaciones métricas asociadas con la forma. La estandarización aplicada en este trabajo se realizó a partir de la Media Geométrica (Darroch y Mosiman 1985), una variable que representa la mejor estimación del tamaño general del hueso.

\section{Resultados}

Pelvis

Al evaluar todas las variables de la pelvis (Figura 1), se
Figura 1: Variables métricas relevadas en la pelvis, a: vista ventral; b: vista dorsal; c: vista craneal del acetábulo; d: vista lateral a la altura del acetábulo; e: acetábulo.

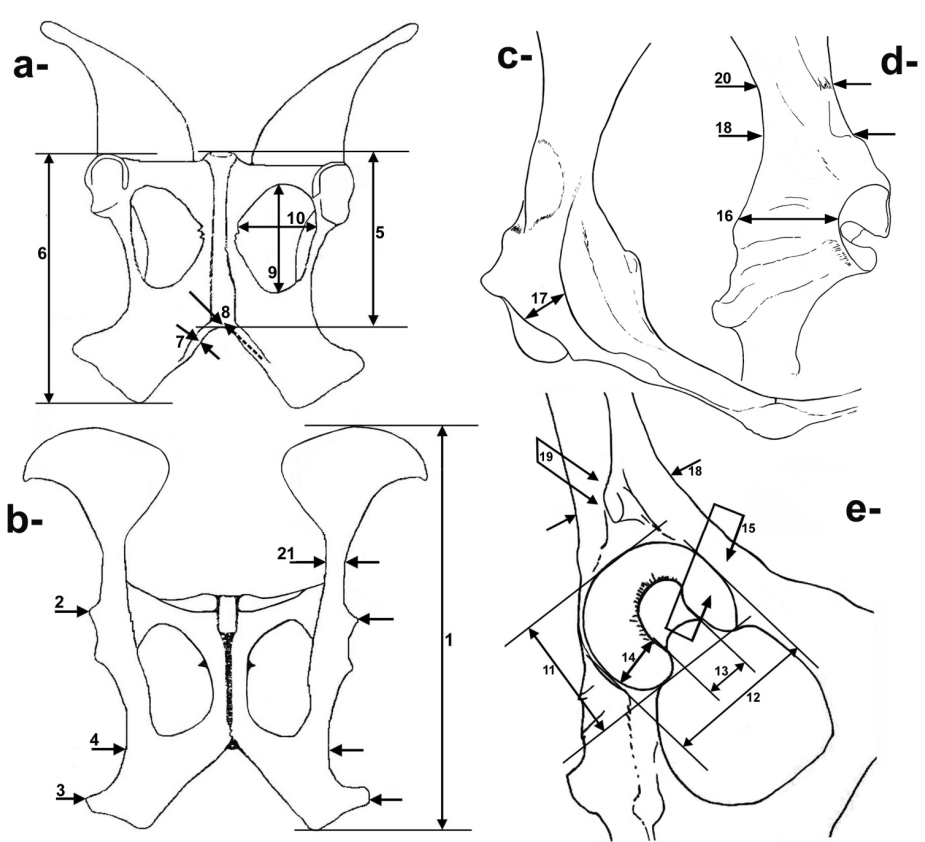


observa que este elemento expresa diferencias entre los sexos a nivel de tamaño. El análisis de ACP con datos no estandarizados de la pelvis completa ( $N$ : 18: 14 hembras y 4 machos) evidencia que las muestras de machos y hembras tienden a separarse a partir del componente 1 (Figura 2a). Las variables con mayor peso del primer componente son: $1 \mathrm{GL}, 6 \mathrm{LIPu}, 2 \mathrm{GBA}$ y $4 \mathrm{SBI}$ y los dos primeros componentes explican el 68,39\% de la variación total. En el ACP con datos estandarizados, las variables 4 SBI, 2 GBA, 1 GL y 3 GBTi presentan mayor peso en la discriminación. En la salida gráfica (Figura 2b) se observa que las muestras se encuentran separadas siguiendo el componente principal 1, solapándose en un solo caso debido a que una de las hembras se ubica dentro de la distribución de machos (los dos primeros componentes explican el 57,34\% de la variación total).

En el análisis de varianza, distintas variables muestran diferencias estadísticas significativas entre machos y hembras $(P<0,05)$. En la mayoría de las mismas, las hembras presentan medias significativamente mayores (variables 2 GBA, 3 GBTi, 4 SBI, 5 LS, 10 BFo: $\mathrm{P}<0$ 0,05; Tabla 1), pero en otras variables los machos registran medias más elevadas y significativas (variables 7 TSTi, 16
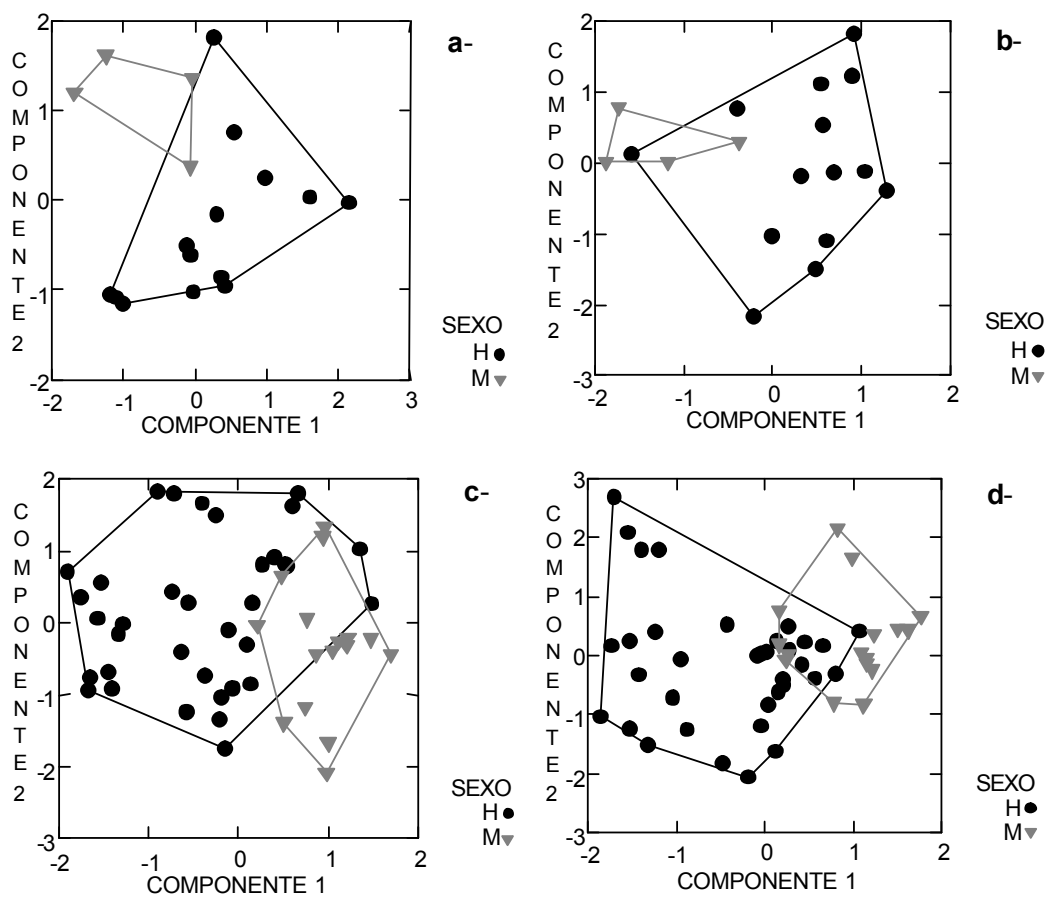

Figura 2. Análisis de componentes principales (ACP) de las pelvis (N: 4 machos; 14 hembras) y acetábulos (N: 16 machos; 36 hembras), a: ACP de las pelvis con datos sin estandarizar; b: ACP de las pelvis con datos estandarizados; c: ACP del acetábulo con datos sin estandarizar; d: ACP del acetábulo con datos estandarizados.

\begin{tabular}{|c|c|c|c|c|c|}
\hline Variable & $\mathrm{N}:$ & Media Cuadrada & $\mathrm{F}$ & $\mathrm{z}$ & Descripción de la Variable \\
\hline $1 \mathrm{GL}$ & 18 & 458,164 & 2,734 & 0,118 & Longitud máxima de la hemipelvis \\
\hline 2 GBA & 18 & 445,789 & 6,425 & 0,022 & Ancho máximo a la altura de los acetábulos \\
\hline $3 \mathrm{GBTi}$ & 18 & 2079,719 & 13,190 & 0,002 & Ancho máximo de las tuberosidades isquiáticas \\
\hline $4 \mathrm{SB} \|$ & 18 & 523,267 & 7,103 & 0,017 & Ancho mínimo lateral de ambos isquiones \\
\hline 5 LS & 18 & 273,396 & 5,510 & 0,032 & Longitud de la sínfisis púbica \\
\hline $6 \mathrm{LIPu}$ & 18 & 16,524 & 0,347 & 0,564 & Longitud diagonal isquio-púbica \\
\hline 7 TSTi & 18 & 7,262 & 8,029 & 0,012 & Espesor de la tuberosidad suspensora del isquion \\
\hline $8 \mathrm{TSPC}$ & 18 & 9,423 & 2,763 & 0,116 & Espesor de la cara ventrocaudal de la sínfisis \\
\hline 9 LFo & 18 & 15,303 & 1,223 & 0,285 & Longitud interna del agujero o foramen obturador \\
\hline 10 BFo & 18 & 52,034 & 4,864 & 0,042 & Ancho máximo del agujero obturador \\
\hline $11 \mathrm{BA}$ & 18 & 4,112 & 2,018 & 0,175 & Ancho del acetábulo \\
\hline 12 LA & 18 & 3,730 & 0,988 & 0,335 & Longitud del acetábulo \\
\hline 13 SDA & 18 & 0,047 & 0,019 & 0,892 & Profundidad mínima del surco acetabular \\
\hline 14 BFvc & 18 & 0,593 & 0,316 & 0,582 & Ancho máximo de la faceta ventrocaudal acetáb. \\
\hline 15 DAvm & 18 & 2,324 & 1,089 & 0,312 & Espesor de la pared ventromedial del acetábulo \\
\hline 16 HIS & 18 & 149,460 & 11,530 & 0,004 & Altura de la espina isquiática \\
\hline 17 HAm & 18 & 35,400 & 4,355 & 0,051 & Altura de la pared medial del acetábulo \\
\hline $18 \mathrm{HII}$ & 18 & 0,047 & 0,007 & 0,936 & Altura diagonal del ilion a la altura del surco \\
\hline $19 \mathrm{BIl}$ & 18 & 4,074 & 3,546 & 0,078 & Ancho del ilion a la altura del surco ilíaco \\
\hline $20 \mathrm{SH}$ & 18 & 1,195 & 0,194 & 0,665 & Altura mínima de la rama del ilion \\
\hline $21 S B$ & 18 & 3,165 & 3,575 & 0,077 & Ancho mínimo de la rama del ilion \\
\hline MG & 18 & 0,011 & 0,003 & 0,957 & Media Geométrica \\
\hline
\end{tabular}

Tabla 1. Estadísticos del ANOVA (one-way) de las variables relevadas en las hemipelvis (N: 18). 
a-

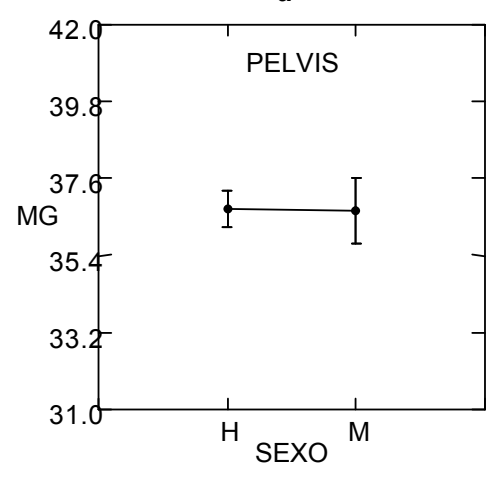

c-

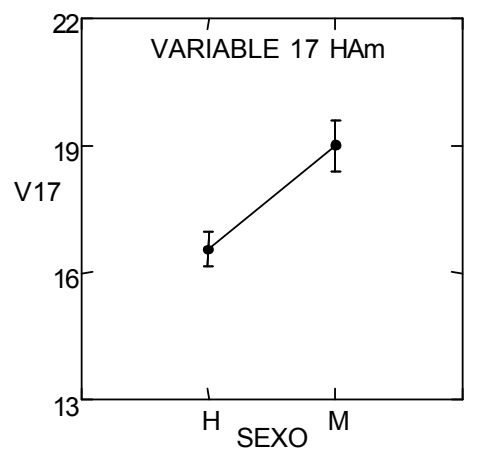

b-

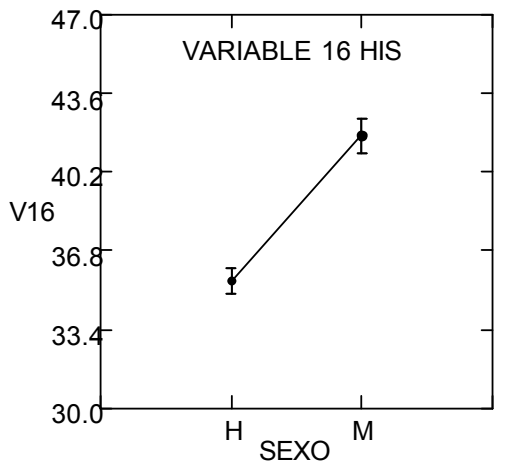

d-

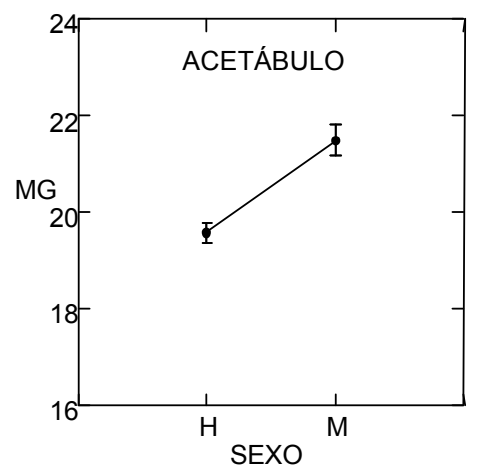

Figura 3: Análisis de varianza. Diferencia de medias entre machos y hembras en las pelvis (N: 4 machos; 14 hembras) y acetábulos (N: 16 machos; 36 hembras), a: Media Geométrica de la pelvis; b: Variable 16 HIS del acetábulo; c: Variable 17 HAm del acetábulo; d: Media Geométrica del acetábulo.

\begin{tabular}{lccrll}
\hline \multicolumn{1}{c}{ Variable } & N: & Media Cuadrada & $\mathrm{F}$ & $\mathrm{P}$ & \multicolumn{1}{c}{ Descripción de la Variable } \\
\hline 11 BA & 51 & 0.392 & 0,210 & 0,649 & Ancho del acetábulo \\
12 LA & 51 & 1.443 & 0,441 & 0,510 & Longitud del acetábulo \\
13 SDA & 51 & 6.000 & 2,418 & 0,126 & Profundidad mínima del surco acetabular \\
14 BFvc & 51 & 2.143 & 1,161 & 0,287 & Ancho máximo de la faceta ventrocaudal acetáb. \\
15 DAvm & 51 & 45.895 & 22,960 & 0,000 & Espesor de la pared ventromedial del acetábulo \\
16 HIS & 51 & 432.023 & 44,790 & 0,000 & Altura de la espina isquiática \\
17 HAm & 51 & 65.848 & 11,320 & 0,001 & Altura de la pared medial del acetábulo \\
\hline MG & 51 & 40.333 & 24,410 & 0,000 & Media Geométrica \\
\hline
\end{tabular}

Tabla 2. Estadísticos del ANOVA (one-way) de las variables relevadas en el acetábulo (N: 51).

HIS y 17 HAm; Tabla 1). La presencia de algunas variables con medias mayores en las hembras y de otras variables con medias mayores en los machos, hace que la Media Geométrica no registre diferencias significativas entre los sexos al evaluar toda pelvis ( $P>0,05$; Figura $3 a$ ).

Debido a que en el estudio de restos osteológicos de guanaco procedentes de sitios arqueológicos resulta poco factible registrar algunas de las diferencias osteométricas halladas en la pelvis completa, se acotó el análisis morfométrico a la región acetabular. Al analizar solamente las variables del acetábulo (Figura 1c-e), la muestra se incrementa notablemente a 51 especímenes (35 hembras y 16 machos). El ACP con variables no estandarizadas muestra que los sexos tienden a separarse a partir del componente principal 1 (Figura 2c), donde las variables 12 LA, 11 BA y 14 BFvc registran el mayor peso (los dos primeros componentes explican el 68,84\% de la variación total). Además, las variables estandarizadas muestran una mejor segregación siguiendo el componente 1 (Figura 2d; los componentes 1 y 2 explican el 70,59\% de la variación total). Estos resultados indican que las diferencias osteométricas halladas entre machos y hembras de Lama guanicoe se relacionan tanto con el tamaño (componente 1 variables sin estandarizar) como con la forma del acetábulo (componente 1 variables estandarizadas).

El análisis de varianza del acetábulo expone que todas las variables registran medias mayores entre los machos (Figura 3 b y c) con claras diferencias estadísticas en las variables 15 DAvm, 16 HIS y $17 \mathrm{HAm}$ ( $\mathrm{P}<0,05$; Tabla 2). Del mismo modo, la Media Geométrica del acetábulo resulta significativamente mayor entre los machos $(\mathrm{P}<$ 0,05; Figura 3d y Tabla 2).

\section{Húmero}

Al analizar el húmero completo (Figura 4 b, d y e; N: 36, 29 hembras y 7 machos), se observa que el análisis de componentes principales con variables sin estandarizar no exhibe una clara separación entre las muestras de 

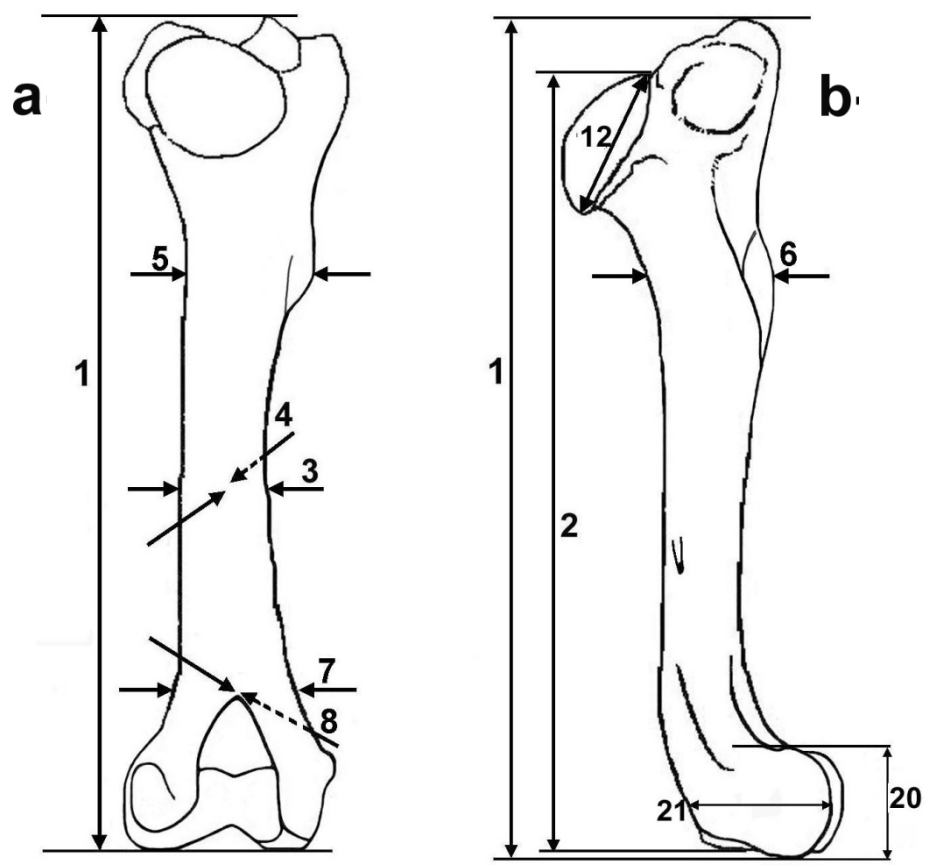

Figura 4: Variables métricas relevadas en el húmero, a: vista posterior del húmero derecho; b: vista lateral; c: epífisis proximal; d: vista anterior de la epífisis distal; e: vista medial de la epífisis distal.

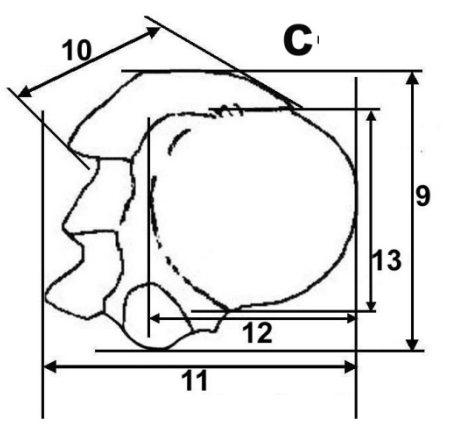

d

e.
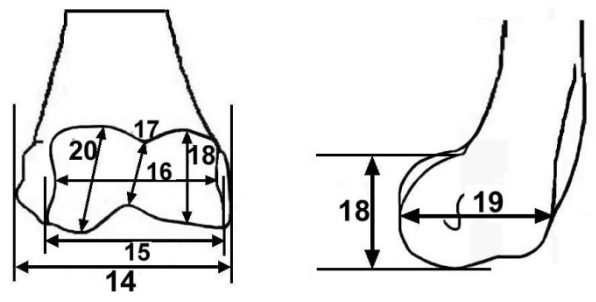

Figura 5. Análisis de componentes principales del húmero completo ( $\mathrm{N}$ : 7 machos; 29 hembras) y de su epífisis distal (N: 8 machos; 32 hembras), a: ACP del húmero completo con datos sin estandarizar; b: ACP del húmero completo con datos estandarizados; C: ACP de la epífisis distal con datos sin estandarizar; d: ACP de la epífisis distal con datos estandarizados.

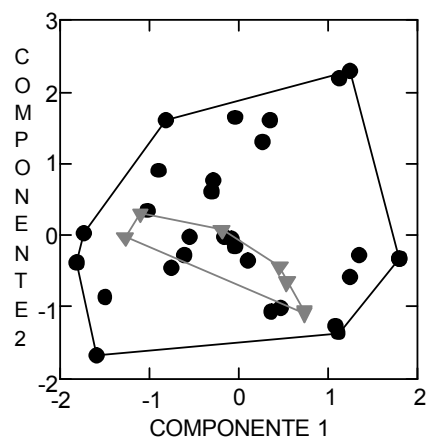

a-

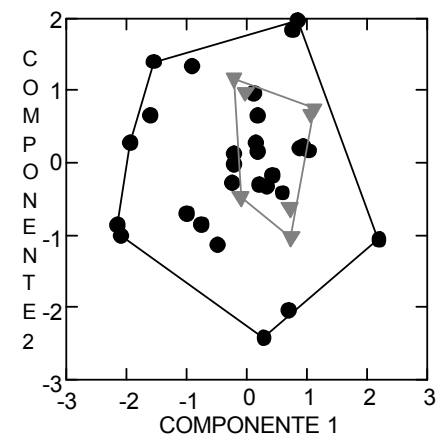

b-

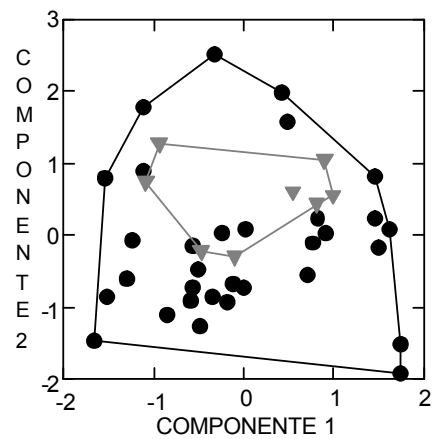

c-

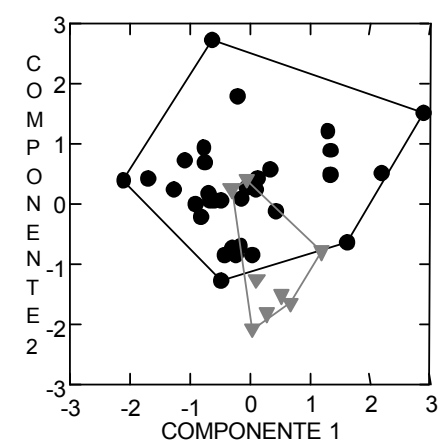

d-

SEXO $\mathrm{M} \vee$ 


\begin{tabular}{|c|c|c|c|c|c|}
\hline Variable & $\mathrm{N}:$ & Media Cuadrada & $\mathrm{F}$ & $\mathrm{P}$ & Descripción de la Variable \\
\hline $1 \mathrm{GL}$ & 36 & 2,230 & 0,023 & 0,881 & Longitud máxima \\
\hline 2 GLC & 36 & 0,335 & 0,004 & 0,950 & Longitud máxima desde la cabeza humeral \\
\hline 3 SD & 36 & 3,484 & 1,991 & 0,167 & Ancho mínimo de la diáfisis \\
\hline $4 \mathrm{DDm}$ & 36 & 0,777 & 0,201 & 0,657 & Profundidad media de la diáfisis \\
\hline 5 GBD & 36 & 6,250 & 0,591 & 0,447 & Ancho máximo de la diáfisis \\
\hline 6 GDD & 36 & 26,342 & 2,845 & 0,101 & Profundidad máxima de la diáfisis \\
\hline $7 \mathrm{BDd}$ & 36 & 6,886 & 2,144 & 0,152 & Ancho distal de la diáfisis \\
\hline $8 \mathrm{DDd}$ & 36 & 0,191 & 0,092 & 0,764 & Profundidad mínima de la diáfisis \\
\hline $9 \mathrm{Bp}$ & 36 & 0,465 & 0,056 & 0,815 & Ancho máximo de la epífisis proximal \\
\hline 10 GDT & 36 & 1,328 & 0,285 & 0,597 & Profundidad máxima de la tuberosidad mayor \\
\hline 11 GDP & 36 & 0,126 & 0,014 & 0,908 & Profundidad máxima de la epífisis \\
\hline $12 \mathrm{DH}$ & 36 & 0,967 & 0,185 & 0,670 & Profundidad de la cabeza humeral \\
\hline $13 \mathrm{BH}$ & 36 & 0,373 & 0,089 & 0,767 & Ancho de la cabeza humeral \\
\hline $14 \mathrm{Bd}$ & 36 & 1,825 & 0,466 & 0,499 & Ancho máximo de la epífisis distal \\
\hline 15 BT & 36 & 3,322 & 1,083 & 0,305 & Ancho máximo de la tróclea \\
\hline 16 BTC & 36 & 2,789 & 0,898 & 0,350 & Ancho mínimo en el centro de la tróclea \\
\hline 17 HTC & 36 & 5,920 & 4,863 & 0,034 & Altura central de la tróclea \\
\hline $18 \mathrm{HTm}$ & 36 & 2,503 & 0,875 & 0,356 & Altura máxima del epicóndilo medial \\
\hline 19 DTm & 36 & 13,735 & 2,331 & 0,136 & Profundidad del epicóndilo medial \\
\hline $20 \mathrm{HTI}$ & 36 & 0,050 & 0,028 & 0,869 & Altura máxima del epicóndilo lateral \\
\hline $21 \mathrm{DTI}$ & 36 & 0,280 & 0,074 & 0,787 & Profundidad del epicóndilo lateral \\
\hline MG & 36 & 0,291 & 0,095 & 0,760 & Media Geométrica \\
\hline
\end{tabular}

Tabla 3. Estadísticos del ANOVA (one-way) de las variables relevadas en el húmero completo (N: 36).

a-
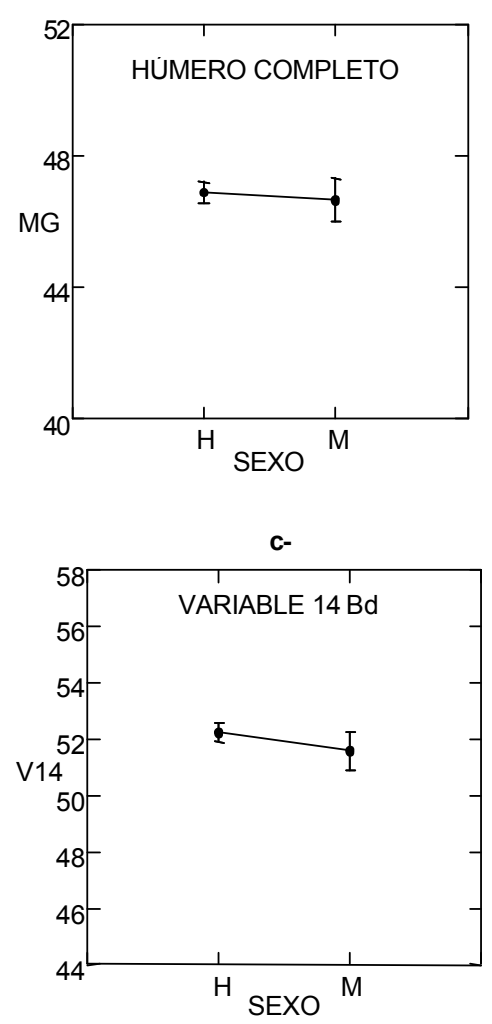

b-
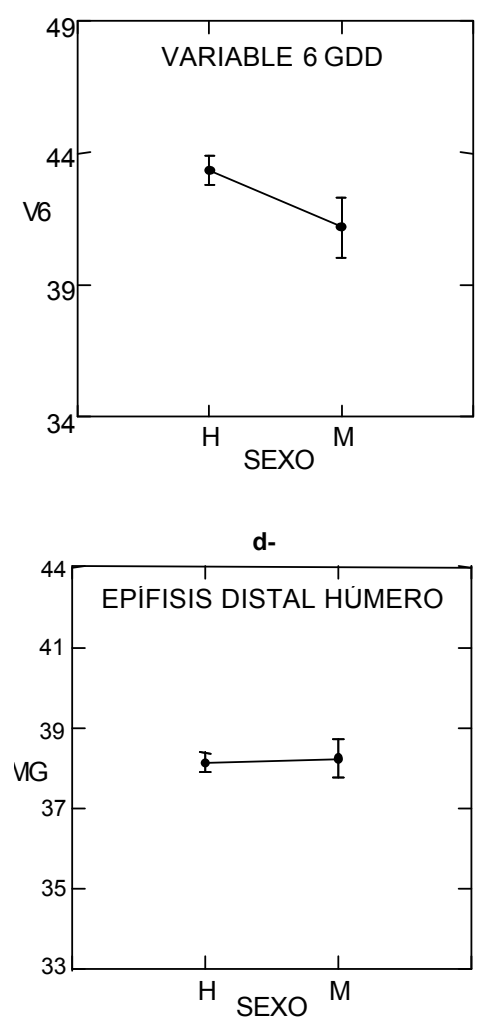

Figura 6. Análisis de varianza. Diferencia de medias entre machos y hembras en el húmero completo (N: 7 machos; 29 hembras) y en su epífisis distal (N: 8 machos; 32 hembras), a: Media Geométrica del húmero completo; b: Variable 6 GDD del húmero completo; c: Variable 14 Bd de la epífisis distal; d: Media Geométrica de la epífisis distal.

machos y hembras. En el eje del componente 1 todos los machos se encuentran comprendidos dentro de la distribución de los tamaños de las hembras -los dos primeros componentes explican el 79,89\% de la variación- (Figura $5 a)$. En el ACP con variables estandarizadas los datos de machos y hembras tampoco se segregan, aunque en este caso el grupo de machos se ubica en el sector de valores positivos del componente 1, dentro de la distribución de los tamaños de las hembras (Figura 5b).

El análisis de varianza no registra diferencias significativas entre los sexos en las variables de la muestra de húmeros completos ( $\mathrm{P}>0,05$; Tabla 3), con excepción de la altura central de la tróclea de la epífisis distal (17 HTC; Tabla 


\begin{tabular}{lcrccl}
\hline Variable & N: & Media Cuadrada & F & P & \multicolumn{1}{c}{ Descripción de la Variable } \\
\hline $14 \mathrm{Bd}$ & 40 & 2,746 & 0,759 & 0,389 & Ancho máximo de la epífisis distal \\
$15 \mathrm{BT}$ & 40 & 3,006 & 1,021 & 0,319 & Ancho máximo de la tróclea \\
$16 \mathrm{BTC}$ & 40 & 2,306 & 0,785 & 0,381 & Ancho mínimo en el centro de la tróclea \\
$17 \mathrm{HTC}$ & 40 & 5,439 & 4,531 & 0,040 & Altura central de la tróclea \\
$18 \mathrm{HTm}$ & 40 & 1,562 & 0,544 & 0,465 & Altura máxima del epicóndilo medial \\
$19 \mathrm{DTm}$ & 40 & 11,020 & 1,911 & 0,175 & Profundidad del epicóndilo medial \\
$20 \mathrm{HTI}$ & 40 & 0,137 & 0,075 & 0,786 & Altura máxima del epicóndilo lateral \\
$21 \mathrm{DTI}$ & 40 & 1,276 & 0,326 & 0,571 & Profundidad del epicóndilo lateral \\
\hline MG & 40 & 0,072 & 0,032 & 0,859 & Media Geométrica \\
\hline
\end{tabular}

Tabla 4. Estadísticos del ANOVA (one-way) de las variables relevadas en la epífisis distal del húmero (N: 40)

3). Igualmente, la Media Geométrica no es significativamente diferente entre hembras y machos para el húmero ( $P>0,05$; Figura 6a), aunque las medias resultan algo más elevadas en el grupo de las hembras (e.g. medida 6 GDD: profundidad máxima de la diáfisis a la altura de la tuberosidad deltoidea; Figura 6b).

Como el interés de este trabajo radica en poder captar la presencia/ausencia y magnitud de las diferencias entre los sexos en los elementos recuperados en el registro arqueológico con el fin de evaluar el dimorfismo sexual de Lama guanicoe, se analiza la epífisis distal del húmero, debido a que este elemento posee una alta probabilidad de hallarse completo y en condiciones de ser medido en muestras arqueológicas (Figura 4d y e; N: 40, 32 hembras y 8 machos).

El análisis de componentes principales con datos estandarizados y no estandarizados expone que toda la variación de tamaños y formas registrada en los machos se encuentra incluida en la variación de tamaños de las hembras. Los dos primeros componentes explican el $82,82 \%$ y $75,51 \%$ de la variación, respectivamente (Figura 5 c y d).

El análisis de varianza de la epífisis distal no exhibe diferencias significativas en la mayoría de las variables (e.g. $14 \mathrm{Bd}$; Figura $6 \mathrm{C}$ ), como así tampoco en la Media Geométrica ( $\mathrm{P}>$ $0,05)$, entendida como medida general del elemento óseo (Figura 6d). Sólo se registra una diferencia significativa para la variable 17 HTC ya mencionada, la cual presenta una media mayor entre las hembras $(P<0,05$; Tabla 4).

\section{Radioulna}

El análisis de PCA con datos no estandarizados de la radioulna completa (Figura 7; N: 35, 25 hembras y 9 machos) presenta una dispersión de los tamaños de hembras y machos similar siguiendo el componente 1 y la distribución de los ejemplares de machos se encuentra

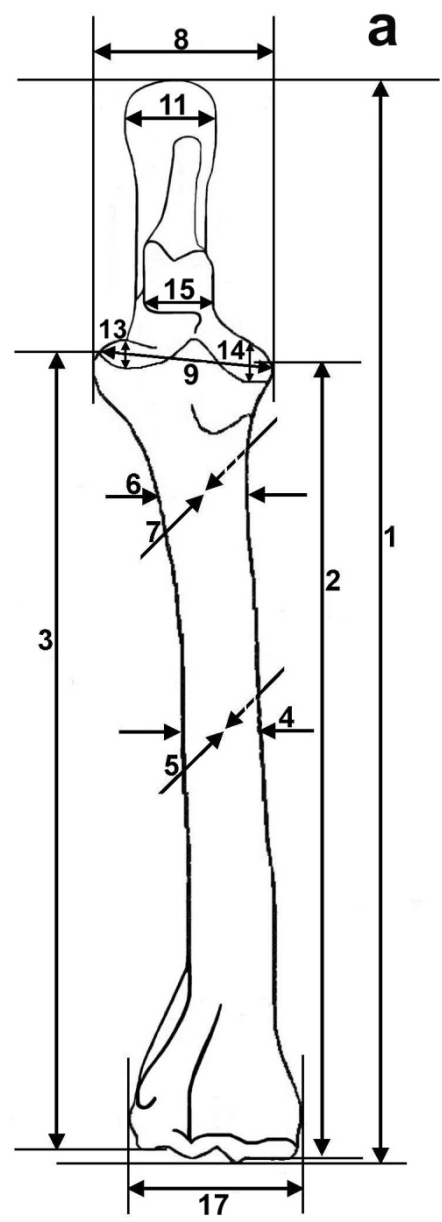

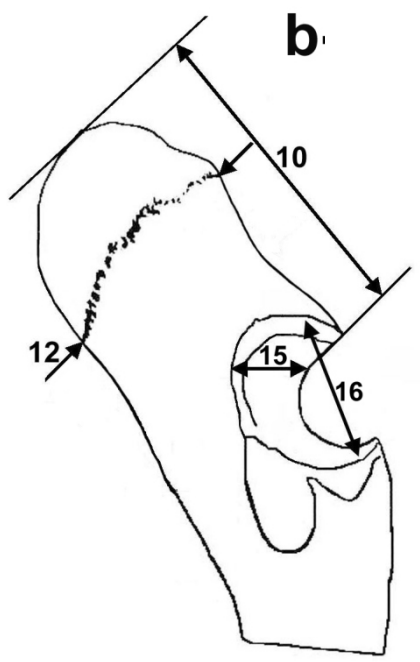

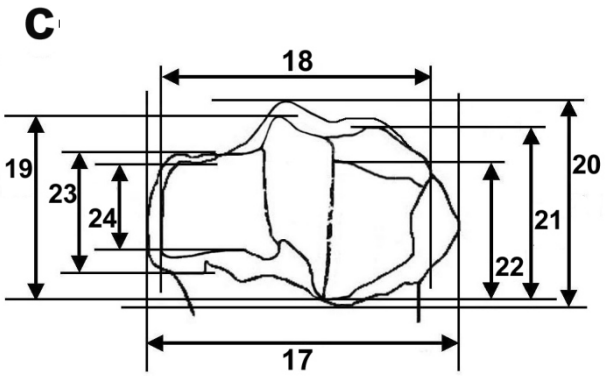

Figura 7: Variables métricas relevadas en la radioulna, a: vista anterior de la radioulna derecha; b: vista lateral de la epífisis proximal; c: epífisis distal. 

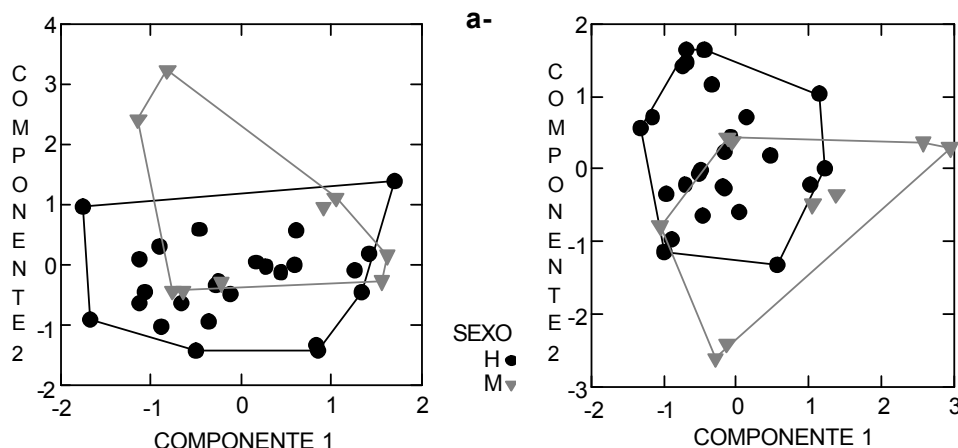

b-
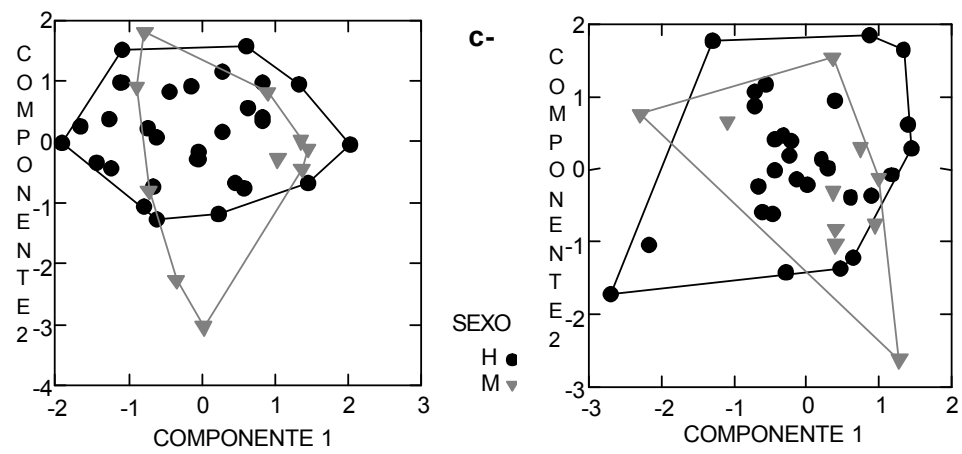

dSEXO $\mathrm{M} \bullet$ SEXO $\mathrm{H} \bullet$

Figura 8. Análisis de componentes principales de la radioulna completa (N: 9 machos; 25 hembras) y de su epífisis distal (N: 10 machos; 29 hembras), a: ACP de la radioulna completa con datos sin estandarizar; b: ACP de la radioulna completa con datos estandarizados; c: ACP de la epífisis distal con datos sin estandarizar; d: ACP de la epífisis distal con datos estandarizados.

\begin{tabular}{llrrrl}
\hline Variable & $\mathrm{N}$ : & Media Cuadrada & \multicolumn{1}{c}{$\mathrm{F}$} & \multicolumn{1}{c}{$\mathrm{P}$} & \multicolumn{1}{c}{ Descripción de la Variable } \\
\hline $1 \mathrm{GL}$ & 34 & 245,597 & 0,947 & 0,338 & Longitud máxima \\
$2 \mathrm{PL}$ & 34 & 340,278 & 1,889 & 0,179 & Longitud fisiológica \\
$3 \mathrm{LI}$ & 34 & 340,615 & 1,928 & 0,175 & Longitud de la parte lateral del radio \\
$4 \mathrm{BDm}$ & 34 & 3,482 & 1,185 & 0,284 & Ancho medio de la diáfisis \\
$5 \mathrm{SDD}$ & 34 & 3,281 & 1,274 & 0,267 & Profundidad mínima de la diáfisis \\
$6 \mathrm{SD}$ & 34 & 0,926 & 0,487 & 0,490 & Ancho mínimo de la diáfisis \\
$7 \mathrm{DDp}$ & 34 & 0,156 & 0,354 & 0,556 & Profundidad proximal de la diáfisis \\
$8 \mathrm{Bp}$ & 34 & 0,520 & 0,161 & 0,690 & Ancho máximo de la epífisis proximal \\
$9 \mathrm{BFp}$ & 34 & 3,011 & 0,893 & 0,352 & Ancho máximo de la faceta articular proximal \\
$10 \mathrm{LO}$ & 34 & 21,990 & 1,509 & 0,228 & Longitud del olecraneon de la ulna \\
$11 \mathrm{BO}$ & 34 & 1,076 & 1,024 & 0,319 & Ancho de la tuberosidad del olecraneon \\
$12 \mathrm{DO}$ & 34 & 2,570 & 0,433 & 0,515 & Profundidad diagonal del olecraneon \\
$13 \mathrm{GDR}$ & 34 & 6,696 & 5,528 & 0,025 & Profundidad máx. de la sup. articular del radio \\
$14 \mathrm{GDC}$ & 34 & 2,267 & 1,456 & 0,236 & Profundidad máx. de la sup. articular de la ulna \\
$15 \mathrm{GBSn}$ & 34 & 0,381 & 0,569 & 0,456 & Ancho máximo de la escotadura semilunar \\
$16 \mathrm{DSn}$ & 34 & 2,224 & 2,001 & 0,167 & Profundidad de la escotadura semilunar \\
$17 \mathrm{Bd}$ & 34 & 4,072 & 1,377 & 0,249 & Ancho máximo de la epífisis \\
$18 \mathrm{BFd}$ & 34 & 4,021 & 1,653 & 0,208 & Ancho máximo de la faceta articular distal \\
$19 \mathrm{GDF}$ & 34 & 1,599 & 1,147 & 0,292 & Profundidad máxima de la faceta articular distal \\
$20 \mathrm{GDd}$ & 34 & 4,048 & 2,309 & 0,138 & Profundidad máxima del proceso articular distal \\
$21 \mathrm{GDm}$ & 34 & 0,041 & 0,042 & 0,839 & Profundidad máxima de la sup. articular medial \\
$22 \mathrm{SDm}$ & 34 & 0,275 & 0,337 & 0,566 & Profundidad mínima de la sup. articular medial \\
$23 \mathrm{GDI}$ & 34 & 0,398 & 0,257 & 0,616 & Profundidad máxima de la sup. articular lateral \\
$24 \mathrm{SDI}$ & 34 & 0,494 & 0,558 & 0,510 & Profundidad mínima de la sup. articular lateral \\
\hline MG & 34 & 0,886 & 0,561 & 0,459 & Media Geométrica \\
\hline
\end{tabular}

Tabla 5. Estadísticos del ANOVA (one-way) de las variables relevadas en la radioulna completa (N: 34$)$.

dentro de los límites de la distribución de las hembras siguiendo el componente 2 (Figura 8a). Los dos primeros componentes principales explican el $56,18 \%$ de la variación. Con los datos estandarizados, el componente 1 del PCA exhibe una dispersión similar para ambos sexos pero, de acuerdo con el componente 2, algunos casos de machos se separan del grupo definido por las hembras (los dos primeros componentes explican el 33,10\%;
Figura 8b). El análisis de varianza no registra diferencias estadísticamente significativas entre hembras y machos en ninguna variable $(P>0,05$; Tabla 5$)$ y, en consecuencia, tampoco en la Media Geométrica (Figura 9a) a pesar que la mayoría de las medidas presentan medias más elevadas entre las hembras (Tabla 5; Figura 9b).

Si se analiza solamente la epífisis distal (Figura 7c; N: 39, 

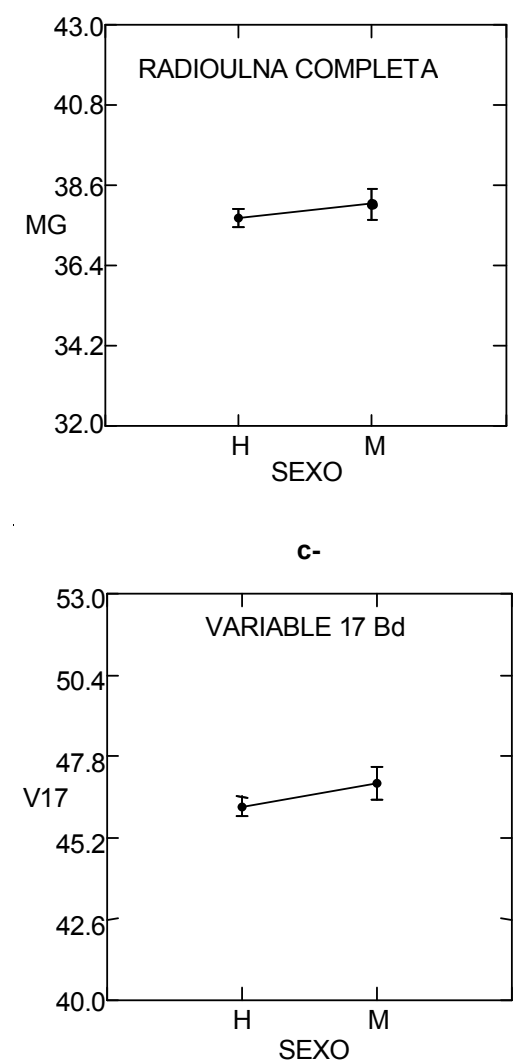

b-

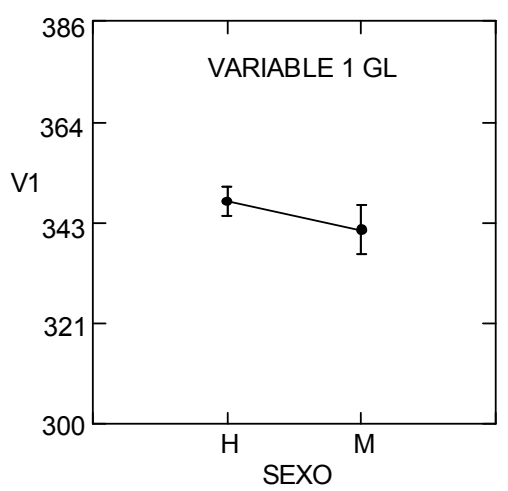

d-

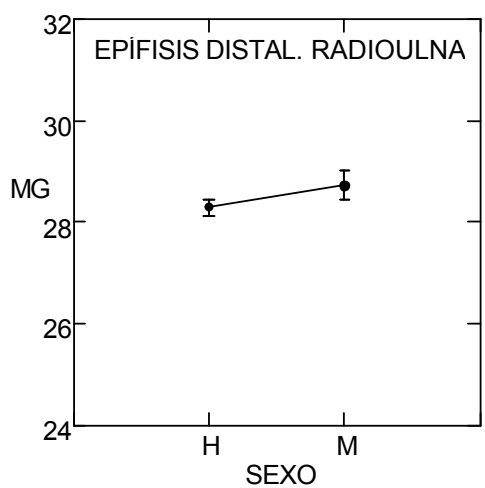

Figura 9. Análisis de varianza. Diferencia de medias entre machos y hembras en la radioulna completa (N: 9 machos; 25 hembras) y en su epífisis distal (N: 10 machos; 29 hembras), a: Media Geométrica de la radioulna completa; b: Variable 1 GL de la radioulna; c: Variable 17 Bd de la epífisis distal; d: Media Geométrica de la epífisis distal.

\begin{tabular}{llrccl}
\hline Variable & N: & Media Cuadrada & F & P & Descripción de la Variable \\
\hline 17 Bd & 39 & 4,097 & 1,431 & 0,239 & Ancho máximo de la epífisis \\
18 BFd & 39 & 4,533 & 1,918 & 0,174 & Ancho máximo de la faceta articular distal \\
19 GDFd & 39 & 2,148 & 1,559 & 0,220 & Profundidad máxima de la faceta articular distal \\
20 GDd & 39 & 4,433 & 2,668 & 0,111 & Profundidad máxima del proceso articular distal \\
21 GDm & 39 & 0,150 & 0,159 & 0,692 & Profundidad máxima de la sup. articular medial \\
22 SDm & 39 & 0,482 & 0,601 & 0,443 & Profundidad mínima de la sup. articular medial \\
23 GDI & 39 & 0,001 & 0,000 & 0,983 & Profundidad máxima de la sup. articular lateral \\
24 SDI & 39 & 0,323 & 0,752 & 0,222 & Profundidad mínima de la sup. articular lateral \\
\hline MG & 39 & 1,339 & 1,656 & 0,206 & Media Geométrica \\
\hline
\end{tabular}

Tabla 6. Estadísticos del ANOVA (one-way) de las variables relevadas en la epífisis distal del radioulna (N: 39).

29 hembras y 10 machos), se observa que la distribución de datos (estandarizados y sin estandarizar) de machos y hembras no se separan a partir del componente 1, quedando los ejemplares de machos incluidos dentro de la dispersión de las hembras (Figuras 8 c y d). Los dos primeros componentes explican el 66,28 \% de la variación. A su vez, el análisis de varianza en la epífisis distal no presenta diferencias significativas a nivel estadístico en ninguna variable ( $P>0,05$; Tabla 6$)$ o en la Media Geométrica ( $P>0,05$; Figura 9 c y d), aunque la mayoría de las dimensiones registran una media levemente mayor entre los machos.

\section{Fémur}

Los datos sin estandarizar del fémur completo (Figura 10; $\mathrm{N}: 36,28$ hembras y 8 machos) no mostraron diferencias en la dispersión de los casos de hembras y machos en el análisis de componentes principales, ya que los machos se encuentran contenidos en la distribución de tamaños de las hembras (Figura 11a). La variabilidad explicada por los dos primeros componentes es del 66,82\%. Con los datos estandarizados se observa un patrón similar, con una mayor dispersión de los casos de machos (Figura 11b). El análisis de la varianza del fémur completo no muestra diferencias significativas entre los sexos en ninguna de las variables, así como tampoco en la Media Geométrica del hueso ( $\mathrm{P}>0,05$; Tabla 7). Igualmente, el grupo de la hembras exhibe algunas variables con medias levemente mayores que la del grupo de machos (Figura 12 a y b).

Al igual que con el elemento completo, en la epífisis proximal del fémur ( $N$ : 40, 33 hembras y 7 machos; Figura 10 b y c) el ACP con datos no estandarizados expone que toda la variación de tamaños de machos se encuentra incluida dentro de la variación de tamaños de las hembras (Figuras 11c). Los dos primeros componentes explican el 78,53\% 
a

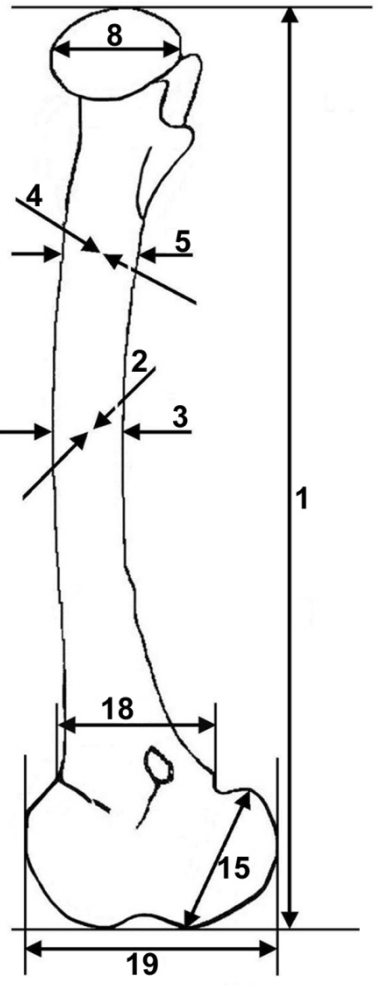

b

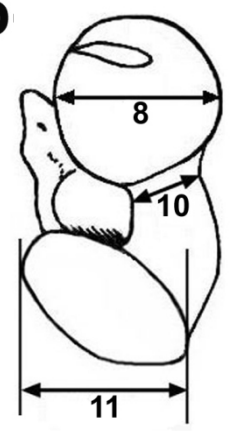

d

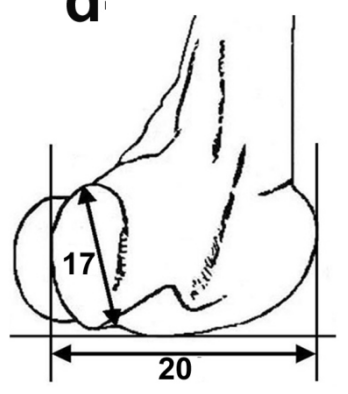

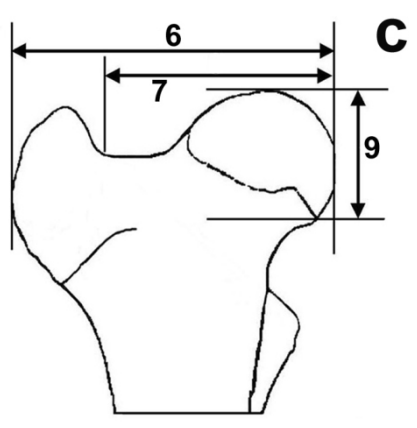

Figura 10: Variables métricas relevadas en el fémur. a: vista medial fémur derecho; $b$ : vista proximal; c: vista anterior de la epífisis proximal; d: vista lateral de la epífisis distal; e: epífisis distal.

Figura 11. Análisis de componentes principales del fémur completo ( $\mathrm{N}: 8$ machos; 28 hembras) y de su epífisis proximal (N: 7 machos; 33 hembras), a: ACP del fémur completo con datos sin estandarizar; b: ACP del fémur completo con datos estandarizados; c: ACP de la epífisis proximal con datos sin estandarizar; $d$ : ACP de la epífisis proximal con datos estandarizados.
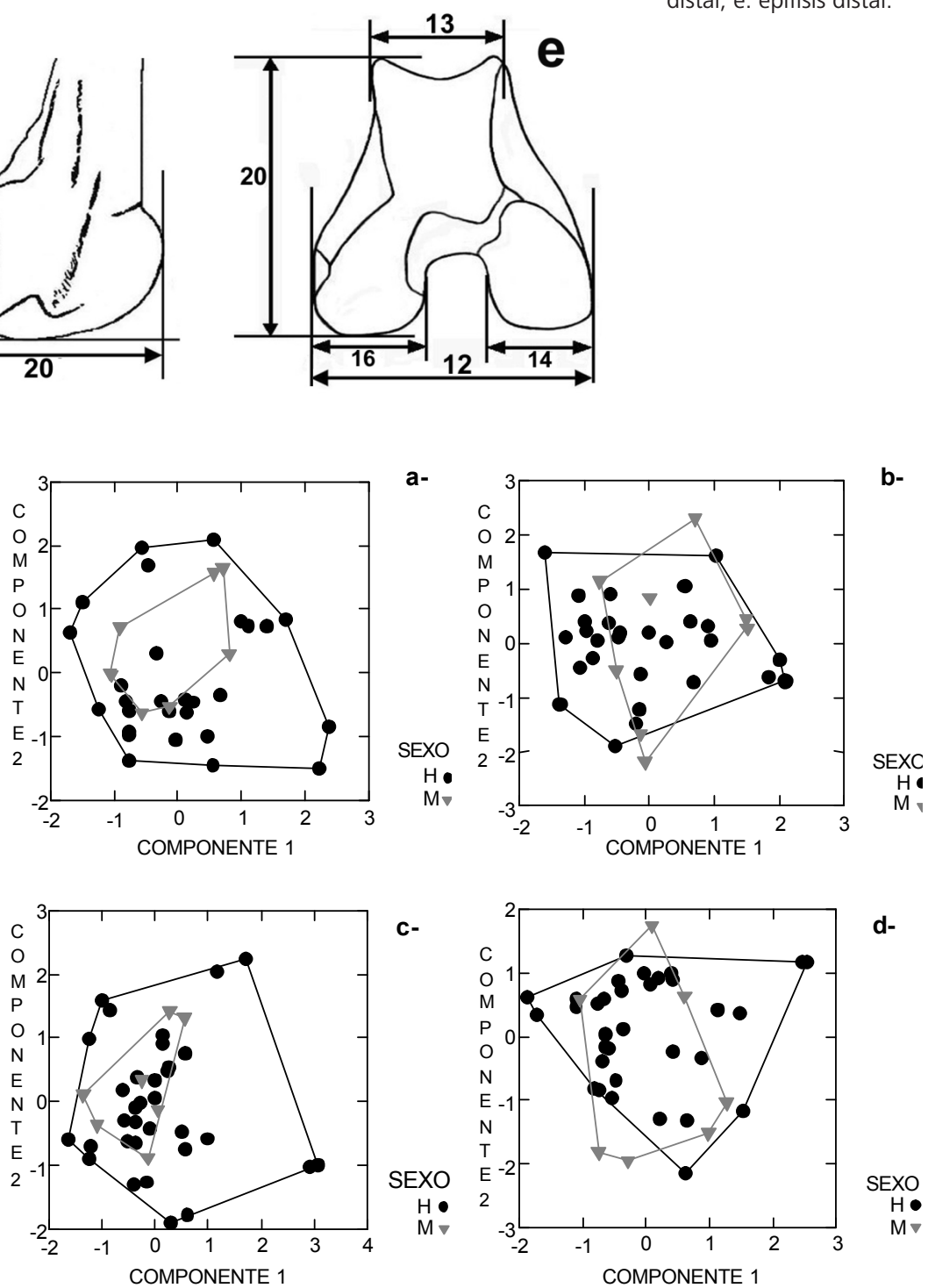

de la variación. Con datos estandarizados, la distribución de machos y hembras tampoco se diferencia siguiendo el componente 1, aunque el conjunto de machos presenta una dispersión mayor (Figura 11d). El análisis de varianza no muestra diferencias significativas entre los sexos en ninguna de las variables ( $P>0,05$; Tabla 8 ), así como tampoco en la Media Geométrica del hueso $(P>0,05$; Figura 12 c y d).

\section{Tibia}

Concordante con lo observado en los demás huesos largos, en la tibia completa (Figura 13; N: 39, 30 hembras y 9 machos) el PCA con datos no estandarizados muestra que, las hembras presentan una distribución de tamaños que comprende al conjunto de machos siguiendo tanto el componente 1 como el 2 (58,41\% de la variación explicada) (Figura 14a). El mismo patrón se observa con los 


\begin{tabular}{llrccl}
\hline Variable & N: & Media Cuadrada & \multicolumn{1}{c}{$\mathrm{F}$} & $\mathrm{P}$ & \multicolumn{1}{c}{ Descripción de la Variable } \\
\hline 1 GL & 36 & 6,406 & 0,034 & 0,856 & Longitud máxima \\
2 SD & 36 & 5,555 & 1,974 & 0,169 & Ancho medio de la diáfisis \\
3 DD & 36 & 2,272 & 0,741 & 0,395 & Profundidad de la diáfisis \\
4 SBLtr & 36 & 0,895 & 0,314 & 0,579 & Ancho mínimo subtrocantéreo \\
5 DDLtr & 36 & 3,753 & 1,077 & 0,307 & Profundidad subtrocantérea \\
6 Bp & 36 & 3,096 & 0,190 & 0,666 & Ancho máximo de la epífisis \\
7 BHN & 36 & 0,976 & 0,080 & 0,779 & Ancho de la cabeza y cuello \\
8 DC & 36 & 0,983 & 0,368 & 0,548 & Profundidad máxima de la cabeza femoral \\
9 GHH & 36 & 2,871 & 1,263 & 0,269 & Altura máxima de la cabeza \\
10 SDN & 36 & 2,355 & 0,994 & 0,326 & Profundidad craneocaudal mínima del cuello \\
11 DGtr & 36 & 3,115 & 1,530 & 0,225 & Profundidad máxima del trocanter mayor \\
12 Bd & 36 & 1,154 & 0,132 & 0,718 & Ancho máximo de la epífisis distal \\
13 GBT & 36 & 0,336 & 0,193 & 0,663 & Ancho máximo de la tróclea \\
14 GBmC & 36 & 0,133 & 0,066 & 0,798 & Ancho máximo del cóndilo medial \\
15 GLmC & 36 & 1,658 & 0,497 & 0,486 & Longitud máxima del cóndilo medial \\
16 GBIC & 36 & 0,163 & 0,044 & 0,835 & Ancho máximo del cóndilo lateral \\
17 GLIC & 36 & 0,154 & 0,046 & 0,831 & Longitud máxima del cóndilo lateral \\
18 DDs & 36 & 10,850 & 2,706 & 0,109 & Profundidad epifisiaria distal \\
19 GDm & 36 & 3,287 & 0,375 & 0,544 & Profundidad medial máxima de la epífisis \\
20 GDI & 36 & 5,040 & 0,542 & 0,467 & Profundidad lateral máxima de la epífisis \\
\hline MG & 36 & 1,265 & 0,481 & 0,493 & Media Geométrica \\
\hline
\end{tabular}

Tabla 7. Estadísticos del ANOVA (one-way) de las variables relevadas en el fémur completo (N: 36).

a-
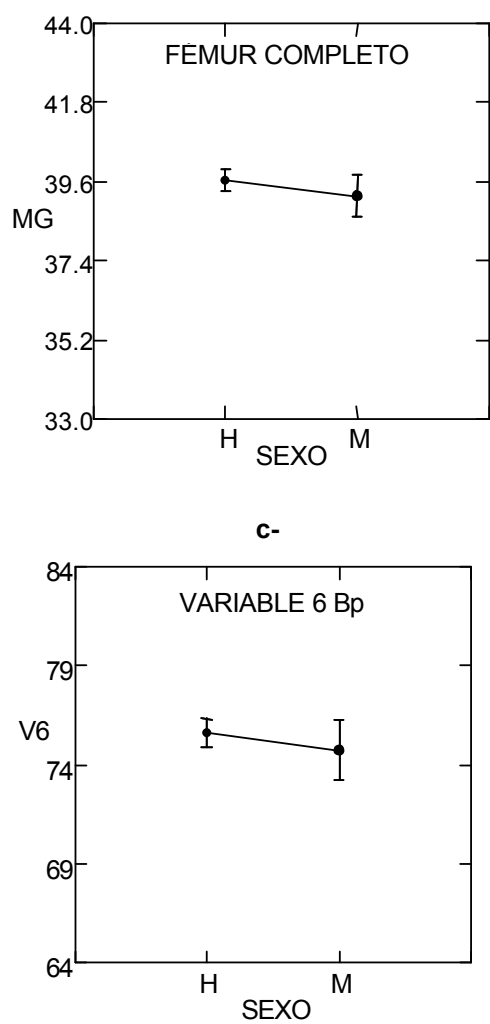

b-

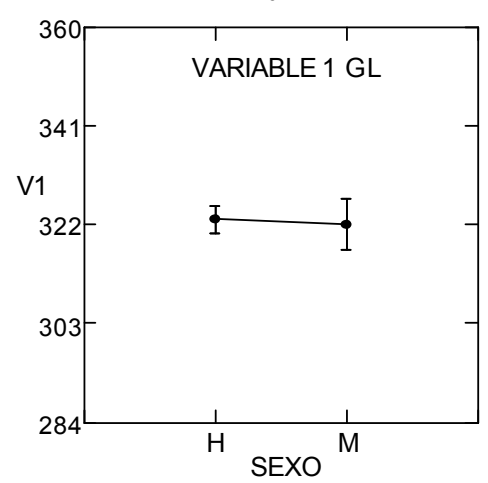

d-

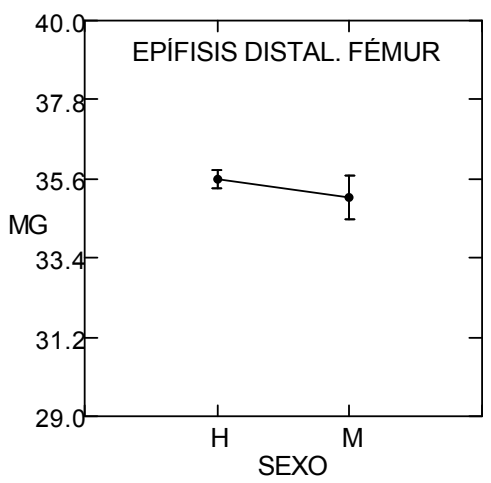

Figura 12. Análisis de varianza. Diferencia de medias entre machos y hembras en el fémur completo (N: 8 machos; 28 hembras) y en su epífisis proximal (N: 7 machos; 33 hembras), a: Media Geométrica del fémur completo; b: Variable 1 GL del fémur completo; c: Variable 6 Bp de la epífisis proximal; d: Media Geométrica de la epífisis proximal.

\begin{tabular}{llrccl}
\hline Variable & N: & Media Cuadrada & F & P & \multicolumn{1}{c}{ Descripción de la Variable } \\
\hline 6 Bp & 40 & 4,495 & 0,283 & 0,598 & Ancho máximo de la epífisis \\
7 BHN & 40 & 3,356 & 0,278 & 0,601 & Ancho de la cabeza y cuello \\
8 DC & 40 & 1,430 & 0,562 & 0,458 & Profundidad máxima de la cabeza femoral \\
9 GHH & 40 & 4,785 & 2,374 & 0,132 & Altura máxima de la cabeza \\
10 SDN & 40 & 1,369 & 0,633 & 0,431 & Profundidad craneocaudal mínima del cuello \\
11 DGtr & 40 & 1,875 & 0,794 & 0,379 & Profundidad máxima del trocanter mayor \\
\hline MG & 40 & 1,421 & 0,577 & 0,452 & Media Geométrica \\
\hline
\end{tabular}

Tabla 8. Estadísticos del ANOVA (one-way) de las variables relevadas en la epífisis proximal del fémur (N: 40). 

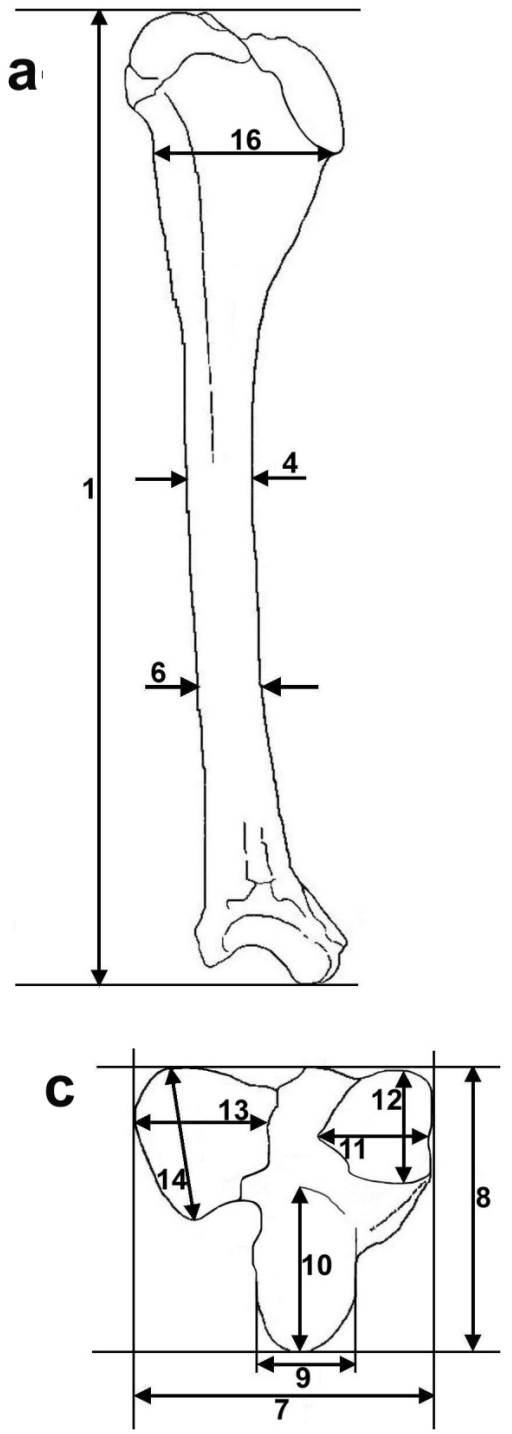

Figura 14. Análisis de componentes principales de la tibia completa ( $\mathrm{N}$ : 9 machos; 30 hembras) y de su epífisis distal (N: 9 machos; 32 hembras), a: ACP de la tibia completa con datos sin estandarizar; b: ACP de la tibia completa con datos estandarizados; c: ACP con de la epífisis distal datos sin estandarizar; d: ACP de la epífisis distal con datos estandarizados. b
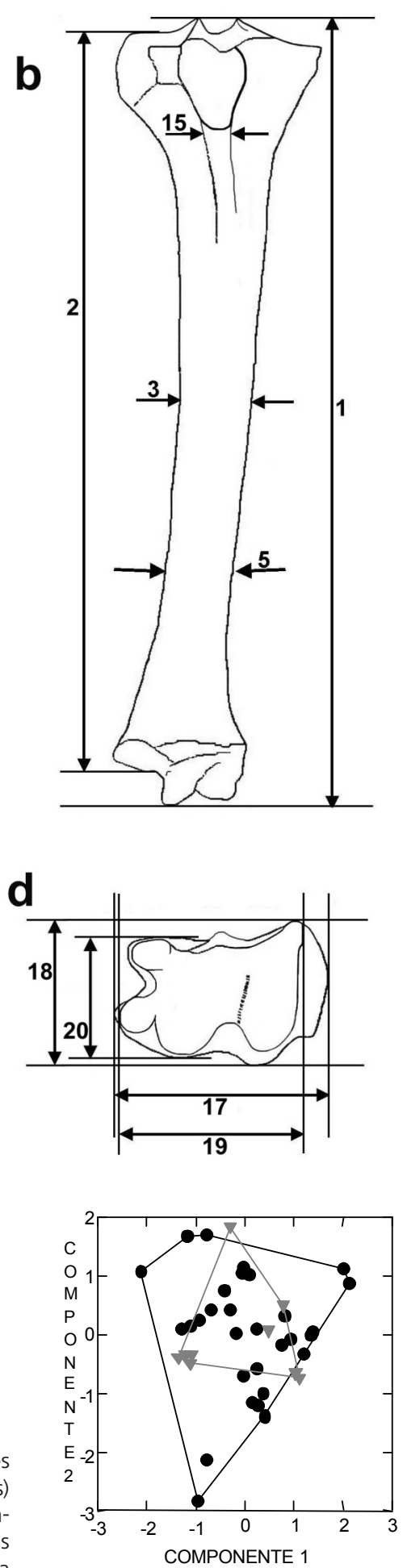

a-
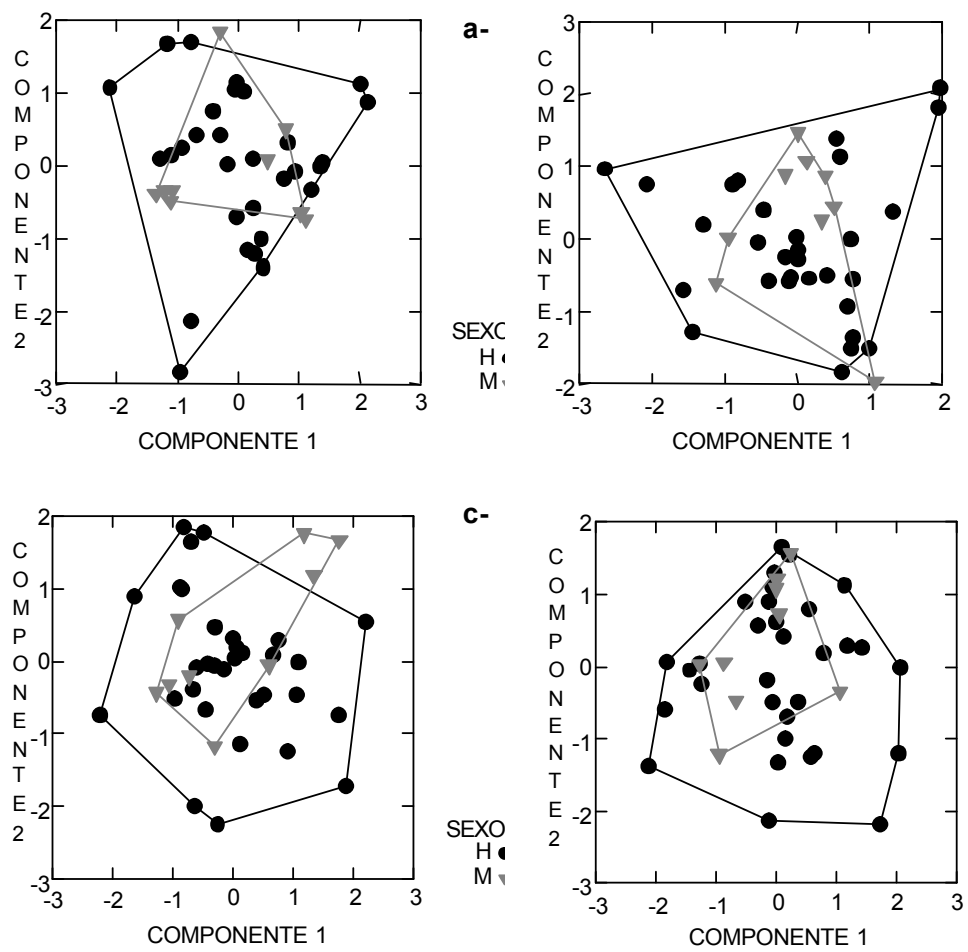

c-

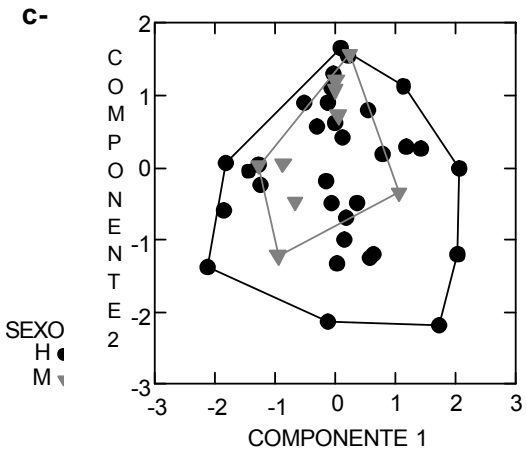

d-

SEXC

$\mathrm{M}$ 甲 


\begin{tabular}{llrlrl}
\hline Variable & N: & Media Cuadrada & \multicolumn{1}{c}{$\mathrm{F}$} & $\mathrm{P}$ & \multicolumn{1}{c}{ Descripción de la Variable } \\
\hline 1 GL & 39 & 285,196 & 0,445 & 0,509 & Longitud máxima \\
2 LI & 39 & 5,181 & 0,036 & 0,851 & Longitud lateral \\
3 BDC & 39 & 1,918 & 1,064 & 0,309 & Ancho central de la diáfisis \\
4 DDC & 39 & 3,570 & 1,274 & 0,266 & Profundidad central de la diáfisis \\
5 SD & 39 & 0,012 & 0,005 & 0,942 & Ancho mínimo de la diáfisis \\
6 SDD & 39 & 2,631 & 2,373 & 0,132 & Profundidad mínima de la diáfisis \\
7 Bp & 39 & 0,341 & 0,046 & 0,831 & Ancho máximo de la epífisis proximal \\
8 GDm & 39 & 9,133 & 0,986 & 0,327 & Profundidad máxima de la epífisis \\
9 GBT & 39 & 3,155 & 2,712 & 0,108 & Ancho máximo de la tuberosidad tibial \\
10 DIE & 39 & 4,637 & 0,938 & 0,339 & Profundidad de la eminencia intercondilar \\
11 BCm & 39 & 1,243 & 0,750 & 0,392 & Ancho de la faceta articular medial \\
12 DCm & 39 & 7,305 & 1,176 & 0,285 & Profundidad máxima de la faceta articular medial \\
13 BCl & 39 & 1,411 & 0,748 & 0,393 & Ancho de la faceta articular lateral \\
14 DCl & 39 & 0,165 & 0,047 & 0,829 & Profundidad máxima de la faceta articular lateral \\
15 BTN & 39 & 0,314 & 0,289 & 0,594 & Ancho del cuello de la tuberosidad \\
16 DMtp & 39 & 11,503 & 1,296 & 0,262 & Profundidad metafisiaria proximal \\
17 Bd & 39 & 3,775 & 1,324 & 0,257 & Ancho máximo de la epífisis \\
18 Dd & 39 & 0,946 & 0,284 & 0,597 & Profundidad máxima de la epífisis \\
19 GBF & 39 & 0,079 & 0,035 & 0,852 & Ancho máximo de la faceta o superficie articular \\
20 SDd & 39 & 0,021 & 0,016 & 0,898 & Profundidad mínima de la epífisis \\
\hline MG & 39 & 0,990 & 0,526 & 0,473 & Media Geométrica \\
\hline
\end{tabular}

Tabla 9. Estadísticos del ANOVA (one-way) de las variables relevadas en la tibia completa (N: 39).

a-
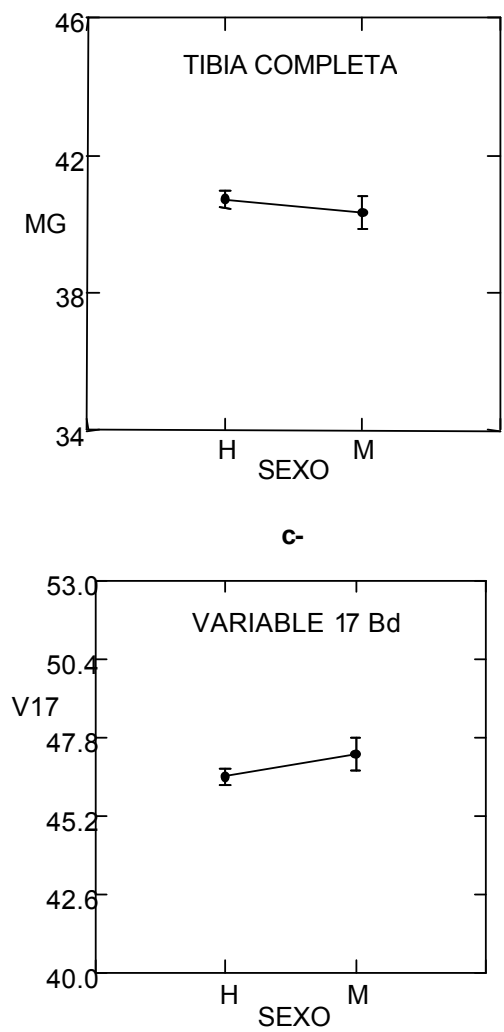

b-

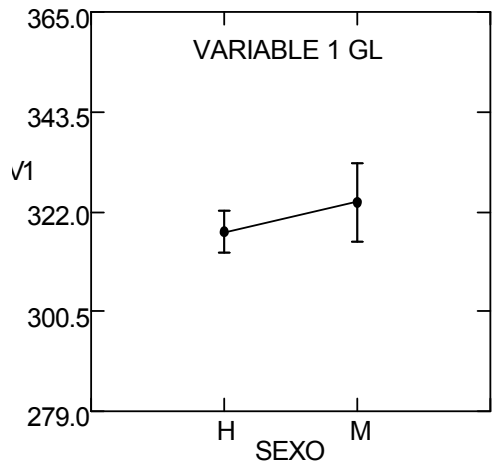

d-

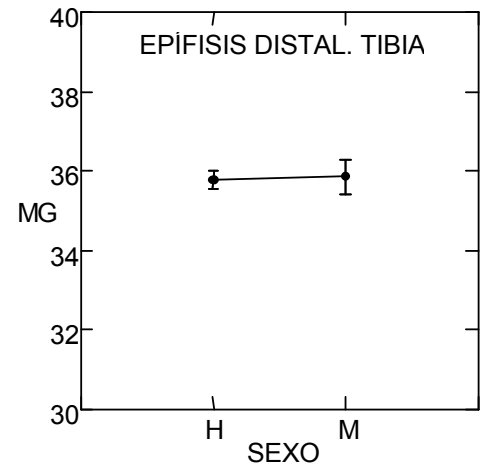

Figura 15. Análisis de varianza. Diferencia de medias entre machos y hembras en la tibia completa (N: 9 machos; 30 hembras) y en su epífisis distal (N: 9 machos; 32 hembras), a: Media Geométrica en la tibia completa; b: Variable 1 GL en la tibia completa; c: Variable 17 Bd de la epífisis distal; d: Media Geométrica de la epífisis distal.

datos estandarizados (Figura 14b). El análisis de varianza de la tibia completa no registra diferencias significativas entre hembras y machos en ninguna de las variables $(P>$ 0,05; Tabla 9). Sólo en la variable $1 \mathrm{GL}$ los machos tienen una media mayor, pero en las otras variables, las hembras presentan medias algo mayores (Figura 15 a y b).

Al analizar solamente la epífisis distal de la tibia, el PCA con datos sin estandarizar (Figura 13d; N: 41, 32 hembras y 9 machos) muestra que la distribución de los datos de machos y hembras no se separan según el componente 1 (Figura 14c). Los dos primeros componentes explican el $86,46 \%$ de la variación. Con datos estandarizados, la distribución de tamaños de los machos queda incluida en la dispersión de las hembras (Figura 14d). El análisis de varianza de la epífisis distal no presenta diferencias significativas a nivel estadístico en ninguna de las variables ( $P$ $>0,05$; Tabla 10). Del mismo modo, la Media Geométrica no resulta significativamente diferente entre los sexos ( $P$ $>0,05$; Figura 15 c y d). 


\begin{tabular}{llrrcl}
\hline Variable & $\mathrm{N}:$ & Media Cuadrada & $\mathrm{F}$ & $\mathrm{P}$ & \multicolumn{1}{c}{ Descripción de la Variable } \\
\hline $17 \mathrm{Bd}$ & 41 & 3,842 & 1,420 & 0,241 & Ancho máximo de la epífisis \\
$18 \mathrm{Dd}$ & 41 & 0,748 & 0,234 & 0,631 & Profundidad máxima de la epíisis \\
$19 \mathrm{GBF}$ & 41 & 0,001 & 0,000 & 0,987 & Ancho máximo de la faceta o superficie articular \\
$20 \mathrm{SDd}$ & 41 & 0,024 & 0,020 & 0,889 & Profundidad mínima de la epífisis \\
\hline MG & 41 & 0,036 & 0,022 & 0,883 & Media Geométrica \\
\hline
\end{tabular}

Tabla 10. Estadísticos del ANOVA (one-way) de las variables relevadas en la epífisis distal de la tibia (N: 41)

\section{Discusión y conclusiones}

Los resultados del análisis morfológico de diferenciación sexual en elementos óseos poscraneales de guanacos mostró que las principales diferencias osteométricas se relacionan con variaciones de tamaño y forma en la pelvis completa y en el acetábulo.

De acuerdo con los análisis métricos realizados en la pelvis, se observa que en las diferencias asociadas con el tamaño, las hembras presentan medias mayores en las variables relacionadas con las dimensiones generales de la pelvis: longitud máxima de la hemipelvis (1 GL), ancho máximo a la altura de los acetábulos (2 GBA), ancho máximo de las tuberosidades isquiáticas (3 GBTi), ancho mínimo lateral entre ambos isquiones (4 SBI), longitud de la sínfisis púbica (5 LS), longitud diagonal isquio-púbica (6 $\mathrm{LIPu})$, longitud interna del agujero o foramen obturador (9 LFo) y ancho máximo del agujero obturador (10 BFo), aunque sólo las variables 2 GBA, 3 GBTi, 4 SBI, 5 LS y 10
BFo resultaron significativamente más grandes entre las hembras a nivel estadístico $(P<0,05)$. Muchas de estas diferencias se relacionan con la función que cumplen estos huesos en la reproducción, ya que al poseer diámetros transversos más grandes que los de los machos, permite que el feto pueda atravesar el canal de parto al producirse el nacimiento (de Lamo 1983; Greenfield 2006). Por el contrario, los machos exhiben medias significativamente mayores $(P<0,05)$ en las regiones óseas relacionadas con la inserción de los músculos suspensores de los testículos: espesor de la tuberosidad suspensora del isquion (7 TSTi).

Debido a que estas variables solamente son apreciadas en pelvis enteras y fusionadas, no resultan de gran utilidad en la identificación sexual en los materiales óseos arqueológicos. Al contrario de lo observado en la pelvis, en la región del acetábulo los machos registran dimensiones superiores en todas las variables analizadas, aunque sólo tres [Espesor de la pared ventromedial del acetábulo (15 DAvm); Altura de la espina isquiática en la fusión lateral

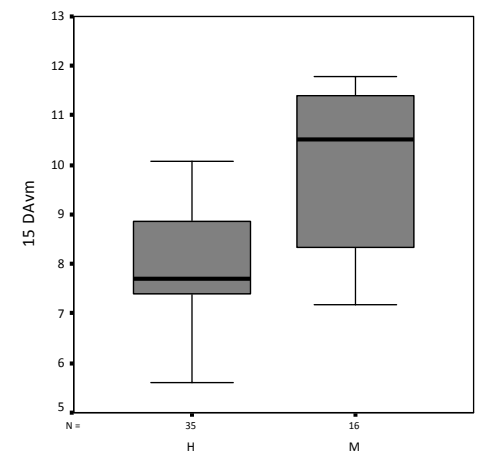

SEXo

a-

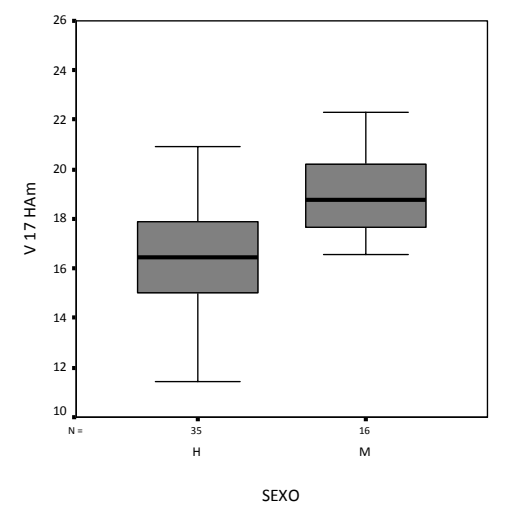

c-

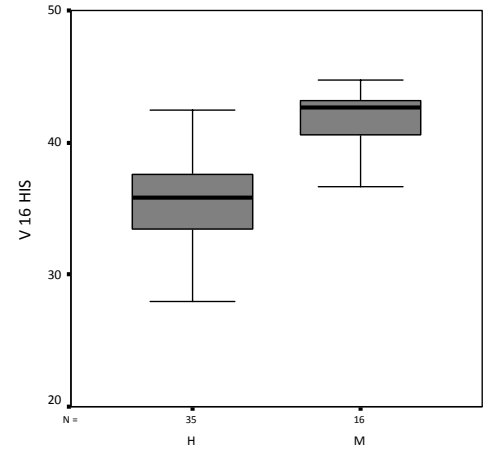

SEXO

b-

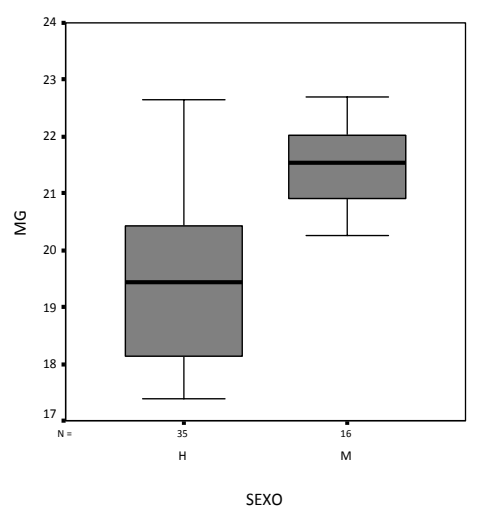

d-

Figura 16. Media y dispersión de las variables del acetábulo (N: 16 machos; 35 hembras), a: Variable 15 DAVm; b: Variable 16 HIS; c: Variable 17 HAm; d: Media Geométrica. 


\begin{tabular}{|c|c|c|c|}
\hline VARIABLES & SEXO & DESCRIPTIVOS & ESTADÍSTICO \\
\hline \multirow[t]{16}{*}{15 DAvm } & \multirow[t]{8}{*}{$\mathrm{H}$} & Media & 7,881 \\
\hline & & Error típ. & ,2122 \\
\hline & & Mediana & 7,690 \\
\hline & & Varianza & 1,576 \\
\hline & & Desv. típ. & 1,2554 \\
\hline & & Mínimo & 5,6 \\
\hline & & Máximo & 10,1 \\
\hline & & Rango & 4,5 \\
\hline & \multirow[t]{8}{*}{$M$} & Media & 9,925 \\
\hline & & Error típ. & ,4299 \\
\hline & & Mediana & 10,515 \\
\hline & & Varianza & 2,957 \\
\hline & & Desv. típ. & 1,7196 \\
\hline & & Mínimo & 7,2 \\
\hline & & Máximo & 11,8 \\
\hline & & Rango & 4,6 \\
\hline \multirow[t]{16}{*}{16 HIS } & \multirow[t]{8}{*}{$\mathrm{H}$} & Media & 35,501 \\
\hline & & Error típ. &, 5641 \\
\hline & & Mediana & 35,830 \\
\hline & & Varianza & 11,139 \\
\hline & & Desv. típ. & 3,3375 \\
\hline & & Mínimo & 28,0 \\
\hline & & Máximo & 42,4 \\
\hline & & Rango & 14,5 \\
\hline & \multirow[t]{8}{*}{$M$} & Media & 41,773 \\
\hline & & Error típ. & ,6257 \\
\hline & & Mediana & 42,630 \\
\hline & & Varianza & 6,263 \\
\hline & & Desv. típ. & 2,5027 \\
\hline & & Mínimo & 36,3 \\
\hline & & Máximo & 44,7 \\
\hline & & Rango & 8,5 \\
\hline \multirow[t]{16}{*}{$17 \mathrm{HAm}$} & \multirow[t]{8}{*}{$\mathrm{H}$} & Media & 16,551 \\
\hline & & Error típ. & ,4507 \\
\hline & & Mediana & 16,480 \\
\hline & & Varianza & 7,109 \\
\hline & & Desv. típ. & 2,6664 \\
\hline & & Mínimo & 11,4 \\
\hline & & Máximo & 23,5 \\
\hline & & Rango & 12,1 \\
\hline & \multirow[t]{8}{*}{$M$} & Media & 19,000 \\
\hline & & Error típ. & ,4244 \\
\hline & & Mediana & 18,775 \\
\hline & & Varianza & 2,881 \\
\hline & & Desv. típ. & 1,6975 \\
\hline & & Mínimo & 16,6 \\
\hline & & Máximo & 22,3 \\
\hline & & Rango & 5,7 \\
\hline
\end{tabular}

Tabla 11. Medidas de centralización y dispersión de las variables significativas del acetábulo (N: 51). del ilion e isquion (16 HIS); Altura de la pared medial del acetábulo (17 HAm)] y la Media Geométrica del acetábulo resultaron significativas $(P<0,05)$.

Al analizar la dispersión de los datos de las variables con diferencias estadísticas (15 DAvm, 16 HIS, 17 HAm, Media Geométrica) se observa que, a pesar que las medias de tamaños difieren significativamente entre los sexos, los rangos de medidas entre machos y hembras se superponen en el acetábulo (Figura 16 a-d y Tabla 11). Entre estas variables, 16 HIS y la Media Geométrica presentan la mejor segregación entre los grupos de hembras y machos, no existiendo superposición en toda la amplitud intercuartil (Figura 16 b y d).

Se considera que todas las variables medidas para el acetábulo, en especial aquellas que tuvieron diferencias significativas entre machos y hembras, son de gran utilidad para discriminar el sexo en guanacos. Esta porción de la pelvis, por su alta densidad mineral ósea, tiene altas chances de conservarse en conjuntos óseos con elevada fragmentación, aumentando la posibilidad de estimar el sexo en un gran número de especimenes arqueológicos. De todos modos, debe tenerse en cuenta que los rangos de medidas presentados (Tabla 11) serían aplicables a poblaciones procedentes de latitudes próximas a la muestra estudiada, ya que se ha observado que los tamaños poblacionales de los guanacos modernos varían de acuerdo con la latitud (e.g. los guanacos de Río Negro son, en promedio, más chicos que los de Santa Cruz; L'Heureux 2009b). Como medida de moderar el efecto de la variabilidad de tamaños entre poblaciones se podrían considerar los datos estandarizados, ya que se ha observado que las diferencias sexuales halladas en el acetábulo involucran tanto el tamaño como la forma del mismo.

Por otro lado, en el resto del esqueleto apendicular, las diferencias osteométricas significativas se registraron solamente en dos variables aisladas de los cuatro huesos largos analizados [variables 17 (HTC: altura central o mínima de la tróclea) en el húmero y 13 (GDR: profundidad máxima de la superficie articular para el radio) en la radioulna], por lo que no se pudieron definir diferencias de tamaños asociadas con el dimorfismo sexual en el esqueleto apendicular. En los húmeros, radioulnas, fémures y tibias (elementos completos o sus epífisis), las hembras exhibieron siempre un rango de tamaño mayor que el observado en los machos, quedando éstos últimos comprendidos dentro de la distribución de las hembras. Igualmente, se considera que la diferenciación sexual en elementos del esqueleto apendicular deberá ser reevaluada en un futuro con mayor profundidad, considerando una muestra más numerosa de individuos machos e incorporando individuos juveniles y subadultos de guanaco. 


\section{Agradecimientos}

Este trabajo forma parte del Programa de Investigación INCUAPA (Secretaría de Ciencia, Arte y Tecnología, Universidad Nacional del Centro de la Provincia de Buenos Aires), dirigido por Gustavo Politis y José L. Prado y fue financiado por el PICT-ANPCyT N 2046 dirigido por el Dr. Luis Borrero (Departamento de Investigaciones Prehistóricas y Arqueológicas, IMHICIHU-CONICET) y el PIP-CONICET 5816/05 dirigido por la Dra. María A. Gutiérrez. Agradecemos a la Lic. María Clara Álvarez, y Daniel Rafusse quienes colaboraron en la corrección de la versión final de este trabajo.

\section{Bibliografía}

Cabrera, A. y A. Willink. 1980. Biogeografía de América Latina. Monografía 13. Secretaría General de la Organización de los Estados Americanos. Programa Regional de Desarrollo Científico y Tecnológico. Washington D.C.

Cartajena, I. 2002. Los conjuntos arqueofaunísticos del Arcaico Temprano en la Puna de Atacama, Norte de Chile. Tesis Doctoral. Freie Universität Berlin. Impresa en microfilm, ABESY Vertriebs GMBH, Alemania. 204 pp.

Cartajena, I. 2007. Una propuesta metodológica para la estandarización de medidas en huesos cortos de camélidos y para la determinación de sexo. Werken 10: 49-62.

Crespo, E. A. 1988. Dinámica poblacional del lobo marino de un pelo, en el norte del litoral patagónico, Tesis doctoral inédita. Facultad de Ciencias Naturales, Universidad Nacional de La Plata, Argentina.

Darroch, J. y J. Mosiman. 1985. Canonical and principal component of shape. Biométrika 72: 241-252.

Davis, S. J. 1987. The archaeology of animals. Yale University Press, New Haven.

Davis, S. J. 1996. Measurements of a group of adult female shetland sheep skeletons from a single flock: a baseline for zooarchaeologist. Journal of Archaeological Science 23: 593-612.

De Lamo, D. A. 1983. Estructura de edades de la población de guanacos, Chubut, Argentina. Informe presentado al Consejo Nacional de Investigaciones Científicas y Técnicas (CONICET). MS.

1990. Determinación de edad en guanacos (Lama guanicoe Müller) por análisis del desarrollo y desgaste dentario. Veterinaria Argentina 7(69): 621-625.

Driesch, A. von den 1976. A guide to the measurement of animal bones from archaeological sites, Peabody Museum Bulletins (1). Harvard University.
Fritz, M. A. 1985. Population dynamics and preliminary estimates of the harvestability of the Patagonian guanaco. Tesis de Maestría inédita. Iowa State University. Ames, lowa. 61 pp.

Greenfield, H. J. 2006.Sexing Fragmentary Ungulate Acetabulae. En Recent Advances in Ageing and Sexing Animal Bones, editado por D. Ruscillo, pp: 68-86. 9th ICAZ Conference, Durham.

Grigson, C. 1982. Sexing Neolithic domestic cattle skulls and horncores. En Ageing and sexing animal bones from archaeological sites, editado por B. Wilson, C. Grigson, y S. Payne, pp. 25-35. Oxford: British Archaeological Reports.

Guarido, J. C. y M. Mazzitelli. 2003. Geografía. El Bajo del Gualicho. En Bajo del Gualicho: una planicie patagónica bajo el nivel del mar. Realidad y leyenda, editado por R. F. Masera y J. C. Guarido, pp. 25-57. Secretaria de Estado de Acción Social de río Negro. Carmen de Patagones, Río Negro.

Higham, C. F. W., Kijngam, A. y B. F. Manly. 1980. An analysis of prehistoric canid remains from Thailand. Journal of Archaeological Science 7: 149-165.

Kaufmann, C. A. 2009. Estructura de Edad y Sexo en Lama guanicoe (Guanaco). Estudios actualísticos y arqueológicos en Pampa y Patagonia. Sociedad Argentina de Antropología.

Kent, J. D. 1982. The Domestication and Exploitation of the South American Camelids: Methods of Analysis and their Application to Circum-lacustrine Archaeological Sites in Bolivia and Peru. Tesis Doctoral inédita, St. Louis, Washington University. 304 pp.

L'Heureux, G. L. 2008. El estudio arqueológico del proceso coevolutivo entre las poblaciones humanas y las poblaciones de guanacos en Patagonia Meridional y Norte de Tierra del Fuego. British Archaeological Reports International Series 1751. Archaeopress, Oxford.

L'Heureux, G. L. 2009a. Guía osteométrica de la cintura pélvica y del esqueleto axial de Lama guanicoe. MS.

L'Heureux, G. L. 2009b. Lama guanicoe (Müller 1776) body size in continental Patagonia and Tierra del Fuego. Trabajo presentado en el $10^{\text {th }}$ International Mammalogical Congress, p. 138. Mendoza.

Lefèvre, C., S. Lepetz y L. Legoupil. 2003. CazadoresRecolectores de Ponsonby (Patagonia Austral) y su Paleomabiente desde VI al III Milenio A.C. Magallania 31: 1-460.

Mengoni Goñalons, G. L. y H. D. Yacobaccio. 2006. The domestication of South American camelids. A view from 
the South-Central Andes. En Documenting domestication. New genetic and archaeological paradigms, editado por M. Zeder, D. Bradley, E. Emshwiller y B. Smith, pp.228-244. University of California Press.

Merino M. L. y J. L. Cajal. 1993. Estructura social de la población de guanacos (Lama guanicoe Müller, 1776) en la costa norte de Península Mitre, Tierra del Fuego. Studies on Neotropical Fauna and Environment 28(3):129-138.

Moore, K. 1989. Hunting and the origin of herding in Peru. Tesis Doctoral, Universidad de Michigan. Impresa en microfilm University Microfilm internacional, Ann Arbor, Michigan.

Morello, J. 1958. La provincia fitogeográfica del Monte. Opera Lilloana 2: 1-155.

Morrison, D. y P. Whitridge. 1997. Estimating the Age and Sex of Caribou from Mandibular Measurements. Journal of Archaeological Science 24: 1093-1106.

O'Connor, T. 2006. Vertebrate demography by numbers: age, sex, and zooarchaeological practice. En Recent Advances in Ageing and Sexing Animal Bones, editado por D. Ruscillo, pp. 1-8. 9th ICAZ Conference, Durham.

Oporto, N., R. Bigatti y E. Larrieu.1979. Determinación de edades en guanaco (Lama guanicoe) en base a su dentición. Revista Argentina de producción animal 4(9): 965-983.

Prummel, W y H. Frisch. 1986. A guide to the distinction of species, sex and body side in bones of sheep and goats. Journal of Archaeological Science 13: 567-578.

Raedeke, K. 1978. El guanaco de Magallanes, Chile. Su distribución y biología. Ministerio de Agricultura de Chile, CONAF. Publicación Técnica 4. MS.

Raedeke, K. 1979. "Population dynamics and sociology of the guanaco (Lama guanicoe) of Magallanes, Chile". Tesis Doctoral inédita. Universidad de Washington, Seattle.

Reher, C. A. y G. C. Frison. 1980. The Vore Site 48CK302: A Stratified Buffalo Jump in the Wyoming Black Hills. Memoir 6: 25(88): 1-190.

Reitz, E. J. y E. S. Wing. 1999. Zooarchaeology. Cambridge Manuals in Archaeology. Cambridge University Press, Cambridge.

Ruscillo, D. 2003. Alternative methods for identifiying sex from archaeological animal bone. En Zooarchaeology in Greece: Recents Advances, editado por Kotjabopoulou, E., Hamilakis, Y., Halstead, P., Gamble, C. y P. Elephanti, pp. 37-44. London.

2006. The Table Test: a Simple Technique for Sexing Canid Humeri. En Recent Advances in Ageing and Sexing Animal Bones, editado por D. Ruscillo, pp. 6267. 9th ICAZ Conference, Durham.

Saba, S. L; D. De Lamo y S. Puig. 1995. Dinámica poblacional del guanaco. En Técnicas para el manejo del guanaco, editado por S. Puig, pp. 71-83. UICN, Mendoza.

Sedlácková, J. 2006. Environment, Body Size and Sexual Dimorphism in Late Glacial Reindeer. En Recent Advances in Ageing and Sexing Animal Bones, editado por D. Ruscillo, pp. 247-253. 9th ICAZ Conference, Durham.

SPSS V.15. 2006. Statistical Package for the Social Sciences for Windows. Version estándar. SPSS Inc. Chicago.

Speth, J. 1983. Bison Kills and Bone Counts: Decision Making by Ancient Hunters. Chicago: University of Chicago Press.

Steele T. E. 2002. Red deer: Their ecology and how they were hunted by Late Pleistocene hominids in western Europe. Tesis Doctoral inédita. Stanford University, Stanford.292 pp.

Steele T. E. 2003. Using Mortality profiles to infer behavior in the fossil record. Journal of Mammalogy, 84(2): 418-430.

Stiner, M. 1990. The use of mortality patterns in archaeological studies of hominid predatory adaptations. Journal of Anthropological Arqueology 9: 305-351.

SYSTAT 10.2. 2002. Statistics and statistical graphics software package. Systat Software Inc. Chicago.

Vilá, B. L. 2000 Comportamiento y organización social de la vicuña. En Manejo Sustentable de la Vicuña editado por Gonzales B., Bas F., Tala C., y A. Iriarte. Pp. 175192. Servicio Agrícola ganadero. Pontificia Universidad Católica de Chile, FIA. SAG. Santiago de Chile.

Weinstock, J. 2000. Osteometry as a source of refined demographic information: sex-ratios of reindeer, hunting strategies, and herd control in the Late Glacial site of Stellmoor, Northern Germany. Journal of Archaeological Science 27: 1187-1195.

Yacobaccio, H. D. 2006. Variables morfométricas de vicuñas (Vicugna vicugna vicugna) en Cieneguillas, Jujuy. En Investigación, conservación y manejo de vicuñas, editado por B. Vilá, pp. 101-112. Proyecto MACS-Argentina, Buenos Aires. 